\title{
Colombia EN 2015: PAZ, ElECCIONES REGIONALES Y RELACIONES ENTRE LAS RAMAS DEL PODER PÚBLICO
}

\author{
Colombia in 2015: Peace, Regional Elections and the Relations \\ Between Branches of Power
}

\author{
LAURA WILLS-OTERO
}

Universidad de los Andes de Bogotá

\section{CARLOS ANDRÉS HOYOS}

Universidad de los Andes de Bogotá

\begin{abstract}
RESUMEN
El siguiente artículo tiene como objetivo reseñar hechos de coyuntura política, económica y social, así como de procesos políticos que se dieron en el interior y entre las tres ramas del poder público del país durante 2015. A lo largo del año, la rama ejecutiva, la legislativa, y la judicial concentraron esfuerzos para crear condiciones encaminadas a una salida negociada del conflicto armado que vive el país. Las elecciones regionales de octubre estuvieron permeadas por la idea de la finalización del conflicto, y por la necesidad de construir una "paz territorial" que tenga en cuenta las condiciones de contexto de cada región del país. En las secciones que siguen hacemos un resumen de algunos eventos que acontecieron en la coyuntura política, social, económica y subregional del país. También presentamos un listado y breve análisis de las reformas constitucionales y de las nuevas leyes sancionadas. En la tercera parte, hacemos un balance de los resultados de las elecciones subnacionales. Posteriormente, describimos aspectos relacionados con la composición del poder ejecutivo y del poder legislativo, y analizamos las relaciones entre las dos ramas. Al final, reflexionamos sobre las relaciones entre los diferentes niveles del gobierno, y sobre el funcionamiento general de la democracia colombiana durante el año.
\end{abstract}

Palabras clave: Proceso de paz, elecciones regionales, coyuntura económica, política y social, ramas legislativa, ejecutiva y judicial.

\section{ABSTRACT}

The aim of this article is to present some of the key events that occurred in the Colombian political, economic, and social spheres, as well as political processes that took place within and among the three branches of power during 2015. During the year, the executive, the legislative, and the judicial branches did efforts to create conditions directed to overcome the armed conflict through peace negotiations. Regional elections that took place in October were permeated by the idea of considering each regions' particular conditions to allow the construction of a territorial peace. In the sections that follow we summarize some facts that occurred in the country over the year. We also present a list and a short analysis of constitutional reforms and new laws that were sanctioned during the year. In the third section, we show subnational electoral results. Then, we describe the composition of the executive and the legislative branches, and we analyze inter-branches relations. Finally, we say something 
about the relations between different levels of government, and about the general functioning of the Colombian democracy.

Key words: Peace process, regional elections, economic, political and social juncture, legislative executive and judicial branches.

\section{COYUNTURA POLÍTICA, SOCIAL, ECONÓMICA Y SUBREGIONAL: ALGUNOS HECHOS QUE MARCARON EL AÑO}

En esta sección presentamos algunos hechos que fueron importantes para el país durante 2015. Por cuestiones de espacio, solo incluimos algunos eventos relevantes que permearon las decisiones de diversos actores en los escenarios políticos y sociales.

\section{Coyuntura política ${ }^{1}$}

En el 2015 se realizaron en el país elecciones regionales en las que se eligieron gobernadores, diputados, concejales, y alcaldes. En la sección 3 resumimos los resultados y mostramos cómo quedó configurado el mapa político regional. En términos generales, los resultados electorales favorecieron a los partidos de la coalición del Gobierno Nacional, esto es el Partido Social de Unidad Nacional (PSUN); el Partido Liberal (PL) y Cambio Radical (CR). Al contrario, los partidos de la oposición, es decir, el Centro Democrático (CD) y el Polo Democrático Alternativo (PDA) se mostraron muy poco fuertes. Para el presidente Santos lograr apoyo en estas elecciones significaba aumentar las probabilidades de obtener respaldo en la "paz regional" que se ha venido negociando en La Habana entre el Gobierno Nacional y el grupo guerrillero Fuerzas Armadas Revolucionarias de Colombia (FARC).

En cuanto al proceso de paz, el año estuvo permeado de momentos críticos tras amenazas a los avances, así como por empeño en sacar adelante el acuerdo. En febrero, las FARC-EP manifestaron su voluntad de renunciar al reclutamiento de menores. En marzo se llegó a un acuerdo de desminado conjunto entre los militares y la guerrilla. Ese mismo mes, el Presidente ordenó la suspensión de bombardeos contra las FARC-EP por un mes. Sin embargo, un mes más tarde, la guerrilla atacó un batallón en el sur del país (v.g., Cauca) en el que murieron once militares. Después de esto, el ejército retomó los bombardeos y en mayo cayeron abatidos 26 guerrilleros. Durante junio y julio hubo hitos importantes como la definición de la creación de una Comisión de Verdad, y la decisión de las FARCEP de hacer una tregua unilateral. El 23 de septiembre se comunicó la firma del cuarto acuerdo entre los dos actores, relacionado con la justicia y la reparación de las víctimas. ${ }^{2}$ Ese mismo día el presidente Santos y el jefe negociador de las FARC, alias Timochenko, se encontraron en La Habana y sellaron un pacto en el que se comprometieron a firmar

Agradecemos a Mariana Gutiérrez Ruiz por su asistencia de investigación en este trabajo.

Los tres acuerdos firmados previamente son: 1) "Hacia un Nuevo Campo Colombiano: Reforma Rural Integral"; 2) "Participación política: Apertura democrática para construir la paz", y 3) "Solución al Problema de las Drogas Ilícitas". 
el acuerdo final el 23 de marzo de 2016. Finalmente, el 16 de diciembre se aprobó en el Senado de la República el último debate de un proyecto de ley que establece la realización de un Plebiscito por la Paz, para que los colombianos refrenden los acuerdos después de la firma final entre el gobierno y las FARC-EP. La sanción presidencial para que dicho proyecto se convierta en ley solo se podrá hacer después de que la Corte Constitucional revise el texto aprobado (Revista Semana, 2015c).

En otros ámbitos, el año empezó con fuertes protestas de miembros del sindicato nacional de la rama judicial (Asonal Judicial) y del Instituto Penitenciario y Carcelario (INPEC), que demandaban mejores condiciones salariales. Por otro lado, la Corte Constitucional de la rama judicial enfrentó una crisis profunda por denuncias formales contra uno de sus magistrados (v.g., Jorge Pretelt), tras conocerse que este habría pedido dinero a cambio de influir en un fallo de tutela a favor de una compañía petrolera (v.g., Fidupetrol).

\section{Coyuntura social}

En el 2015 el Gobierno Nacional promovió políticas con gran impacto social. Por una parte, el Ministerio de Educación puso en marcha el programa "Ser Pilo Paga", que otorgó en ese momento 10.000 becas de educación superior en universidades privadas a los mejores estudiantes de las escuelas públicas. Por otro lado, el Ministerio de Vivienda siguió una política iniciada en 2013 mediante la cual se entregarán cien mil viviendas gratis a los sectores más pobres de la población.

Por otro lado, a comienzos del año fue noticia la alarmante propagación del virus conocido como Chikunguña, que en enero ya había afectado a más de 7.000 personas en algunas zonas del país. Este hecho prendió las alarmas del Ministerio de Salud y Protección Social, que tuvo que invertir gran parte de sus esfuerzos en atender casos, y en hacer campañas de prevención (El Tiempo, 2015b). Por otro lado, un tema que tuvo resonancia en la opinión pública giró en torno al enfrentamiento entre el servicio de taxis amarillos y el servicio de carros privados Uber. Estos últimos entraron en competencia no regulada que perjudicó a los segundos. El tema siguió causando revuelo hasta el anuncio del gobierno de expedir un marco regulatorio que establezca las condiciones de prestación de servicios de transporte individual.

\section{Coyuntura económica}

En el plano económico, el balance del 2015 no fue muy alentador. Los eventos más destacados estuvieron relacionados con la fuerte sequía producto del fenómeno de El Niño, que tuvo un impacto negativo en varios sectores productivos del país. Relacionado con lo anterior, se desató una crisis en el sector energético, que puso a varias termoeléctricas fuera de funcionamiento, y que obligó al gobierno a buscar soluciones financieras de emergencia. Por su parte, las acciones de Ecopetrol, la empresa de petróleo más grande del país, sufrieron bajas importantes como consecuencia de la baja internacional de los precios del petróleo. En agosto, la devaluación del dólar sobrepasó el máximo precio histórico en el país al cotizarse por encima del umbral de los tres mil pesos. Esto encareció 
las materias primas y los bienes importados, y aumentó la deuda externa del gobierno y del sector privado (Revista Semana, 2015d). Paralelamente, la inflación superó el 6\%. Por otro lado, el gobierno impulsó una nueva reforma tributaria que incluyó alzas en los gravámenes a la riqueza y a las utilidades de las empresas. Además de esta reforma, se decidió mantener el impuesto del 4 por mil (Revista Portafolio, 2015). En la Tabla 1 se muestran algunos indicadores económicos desde 2011 hasta 2015.

Tabla 1. Indicadores económicos en Colombia, 2011-2015

\begin{tabular}{|c|c|c|c|c|c|}
\hline & 2011 & 2012 & 2013 & 2014 & 2015 \\
\hline PIB per cápita $(\%)^{3}$ & 6,6 & 4,0 & 4,9 & 4,6 & 3,1 \\
\hline Inflación (\%anual) ${ }^{4}$ & 3,73 & 2,44 & 3 & 3,66 & 6,77 \\
\hline Desempleo total $(\%)^{5}$ & 9,7 & 10,4 & 9,2 & 9,1 & 8,6 \\
\hline Déficit $(\% \mathrm{PIB})^{6}$ & $-2,2$ & 3 & 3,6 & 5 & 7,7 \\
\hline Precio Dólar (TRM) ${ }^{7}$ & $1.942,70$ & $1.768,23$ & $1.926,83$ & $2.392,46$ & 3.149 .47 \\
\hline
\end{tabular}

Fuentes: Banco de la República, Banco Mundial y Dane.

\section{Coyuntura subregional e internacional}

Para terminar esta sección es importante resaltar algunos asuntos de la política exterior colombiana durante 2015. En primer lugar, al igual que otros temas, varias de las acciones en este campo estuvieron permeadas por la agenda de paz y las negociaciones entre el Gobierno Nacional y las FARC-EP en La Habana. El presidente Santos siguió en su esfuerzo por invitar a actores y organizaciones internacionales para que verifiquen el proceso, y el cumplimiento de los acuerdos de paz. La UNASUR; el Consejo de Seguridad de la ONU; un delegado especial de Estados Unidos, Bernie Aronson y el Vaticano, entre otros, recibieron llamados por parte del gobierno para cumplir roles de facilitación, mediación, y verificación el proceso (Borda, 2015).

Por otro lado, un tema que no ha dejado de ser álgido en el país, tiene que ver con el manejo de la frontera con Venezuela. En agosto, el presidente Nicolás Maduro tomó la decisión de cerrar la frontera. Después de esto, hubo deportaciones masivas de residentes colombianos e infracciones a los derechos humanos de dicha población. ${ }^{8}$ Finalmente, el presidente Santos anunció en diciembre la eliminación de la visa Schengen, lo que le permite a los colombianos entrar a 26 países en Europa sin necesidad de usar este documento.

\footnotetext{
http:/ / databank.worldbank.org/data/reports.aspx?source=2\&country=COL\&series=\&period=.

Banco de la República.

DANE.

Banco de la República.

Tasas representativas del mercado a diciembre 31 del año reportado.

Según cifras de la ONU, cerca 1.600 colombianos fueron deportados, y cerca de 19.700 que vivían en Venezuela fueron presionados para retornar al país (El Heraldo, 2015).
} 


\section{CAMBIOS INSTITUCIONALES (Y CONSTITUCIONALES) Y CAMBIOS SUSTANCIALES EN POLÍTICAS PÚBLICAS}

A lo largo del 2015, el presidente Juan Manuel Santos sancionó en el Congreso de la República quince nuevas leyes ordinarias, dos reformas constitucionales y una ley estatutaria. De estas, la mayoría (doce) fueron de iniciativa ejecutiva, es decir, sus autores fueron ministros del gabinete del gobierno. Cinco fueron de iniciativa legislativa, y una de otras entidades. Estos hechos van en consonancia con lo que la literatura ha concluido sobre el poder más eficiente de los Presidentes en las democracias presidencialistas latinoamericanas, con respecto a las asambleas legislativas (Cox y Morgenstern, 2001). En la Tabla 2 se presenta un listado de estas leyes, los temas sobre los que versan, el tipo de iniciativa y las fechas de radicación y de sanción.

Tabla 2. Leyes y reformas constitucionales sancionadas en 2015

\begin{tabular}{|c|c|c|c|c|c|}
\hline & Título & Tema & Iniciativa & $\begin{array}{l}\text { Fecha de } \\
\text { radicación }\end{array}$ & $\begin{array}{l}\text { Fecha de } \\
\text { sanción }\end{array}$ \\
\hline & \multicolumn{5}{|c|}{ Proyectos de Ley Ordinarios } \\
\hline 1 & $\begin{array}{l}\text { "Por la cual se dictan disposiciones } \\
\text { en materia de promoción y protección } \\
\text { del derecho a la participación } \\
\text { democrática. [Participación } \\
\text { ciudadana]" }\end{array}$ & $\begin{array}{l}\text { Participación } \\
\text { ciudadana }\end{array}$ & Gubernamental & 03/11/2011 & $06 / 07 / 2015$ \\
\hline 2 & $\begin{array}{l}\text { Por medio de la cual se regula el } \\
\text { derecho fundamental de petición } \\
\text { y se sustituye un título del Código } \\
\text { de Procedimiento Administrativo y } \\
\text { de lo Contencioso Administrativo. } \\
\text { [Derecho de petición] }\end{array}$ & $\begin{array}{l}\text { Derechos } \\
\text { Fundamentales }\end{array}$ & Otras entidades & $25 / 07 / 2012$ & $30 / 06 / 2015$ \\
\hline 3 & $\begin{array}{l}\text { Por medio de la cual se aprueba el } \\
\text { "Acuerdo para el establecimiento } \\
\text { del Fondo de Cooperación de la } \\
\text { Alianza del Pacífico", suscrito en } \\
\text { Cali, República de Colombia, el } 22 \text { de } \\
\text { mayo de 2013. [Fondo de cooperación } \\
\text { Alianza del Pacífico] }\end{array}$ & $\begin{array}{l}\text { Política } \\
\text { Internacional }\end{array}$ & Gubernamental & $03 / 09 / 2013$ & $30 / 01 / 2015$ \\
\hline 4 & $\begin{array}{l}\text { Por la cual se reestructura la Justicia } \\
\text { Penal Militar o Policial, se establecen } \\
\text { requisitos para el desempeño de } \\
\text { sus cargos, se implementa su } \\
\text { Fiscalía General Penal Militar y } \\
\text { Policial, se organiza su Cuerpo } \\
\text { Técnico de Investigación, se señalan } \\
\text { disposiciones }\end{array}$ & $\begin{array}{l}\text { Seguridad, } \\
\text { defensa y fuerza } \\
\text { pública }\end{array}$ & Gubernamental & $11 / 09 / 2013$ & $23 / 07 / 2015$ \\
\hline 5 & $\begin{array}{l}\text { Por medio de la cual se adoptan } \\
\text { instrumentos para prevenir, controlar } \\
\text { y sancionar el contrabando, el } \\
\text { lavado de activos y la evasión fiscal. } \\
\text { [Medidas contra el contrabando, } \\
\text { lavado y evasión] }\end{array}$ & Justicia & Gubernamental & $17 / 09 / 2013$ & $06 / 07 / 2015$ \\
\hline
\end{tabular}




\begin{tabular}{|c|c|c|c|c|}
\hline Título & Tema & Iniciativa & $\begin{array}{l}\text { Fecha de } \\
\text { radicación }\end{array}$ & $\begin{array}{c}\text { Fecha de } \\
\text { sanción }\end{array}$ \\
\hline
\end{tabular}

Por medio de la cual se aprueba el "Tratado de Libre Comercio entre la 6 República de Colombia y la República de Costa Rica", suscrito en Cali, República de Colombia, el 22 de mayo de 2013. [TLC con Costa Rica]

Por la cual se crea el tipo penal de feminicido como delito autónomo y se dictan otras disposiciones. [Rosa Elvira Cely, Feminicidio]

Por medio del cual se modifica la Ley N ${ }^{\circ} 1482$ de 2011, para sancionar 8 penalmente la discriminación contra las personas con discapacidad. [Discriminación discapacitados]

Política

Internacional

Gubernamental

$17 / 09 / 2013 \quad 15 / 07 / 2015$

Mujer Legislativa

$25 / 09 / 2013 \quad 06 / 07 / 2015$

Justicia

Legislativa

$23 / 01 / 2014$

03/06/2015

Por medio de la cual se le otorga la Categoría de Distrito a Riohacha, 9 capital del departamento de $\mathrm{La}$ Guajira. [Distrito Especial Turístico y Cultural de Riohacha]

Por medio de la cual se declara patrimonio cultural inmaterial de la nación la celebración de la Semana Santa en Tunja (Boyacá) y se dictan otras disposiciones. [Celebración Semana Santa de Tunja]

Por la cual se establece el procedimiento disciplinario que deberá seguirse para tramitar y decidir los asuntos disciplinarios que conoce el Consejo Profesional Nacional de Arquitectura y sus Profesiones Auxiliares. [Consejo Profesional Nacional de Arquitectura]

Por medio de la cual se modifica parcialmente la Ley 906 de 2004 en relación con las medidas de aseguramiento privativas de la libertad. [Regulación detención preventiva]

Por la cual se expide el Plan Nacional de Desarrollo 2014 -2018 "Todos por un nuevo país" [Plan Nacional de Desarrollo]
Ordenamiento

Territorial

Celebraciones, honores y monumentos

\section{Profesiones}

Legislativa

$10 / 10 / 2014 \quad 23 / 10 / 2015$

Legislativa

07/05/2014 24/07/2015

Legislativa

10/09/2014 07/09/2015
Gubernamental

(Ministerio de

Justicia y Fiscalía 28/10/2014 06/07/2015

General de la

Nación)

Plan Nacional de

Desarrollo

Gubernamental
(Ministerio de
Hacienda)
06/02/2015 09/06/2015 


\begin{tabular}{|c|c|c|c|c|c|}
\hline & Título & Tema & Iniciativa & $\begin{array}{l}\text { Fecha de } \\
\text { radicación }\end{array}$ & $\begin{array}{l}\text { Fecha de } \\
\text { sanción }\end{array}$ \\
\hline 14 & $\begin{array}{l}\text { Por la cual se decreta el Presupuesto } \\
\text { de Rentas y Recursos de Capital } \\
\text { y Ley de Apropiaciones para la } \\
\text { vigencia fiscal del } 1^{\circ} \text { de enero al } 31 \\
\text { de diciembre de } 2016 \text {. [Presupuesto } \\
\text { General de la Nación 2016] }\end{array}$ & Presupuesto & $\begin{array}{l}\text { Gubernamental } \\
\text { (Ministerio de } \\
\text { Hacienda) }\end{array}$ & $29 / 07 / 2015$ & $24 / 11 / 2015$ \\
\hline 15 & $\begin{array}{l}\text { Por la cual se amplían las } \\
\text { autorizaciones conferidas al Gobierno } \\
\text { nacional para celebrar operaciones } \\
\text { de crédito público externo e interno } \\
\text { y operaciones asimiladas a las } \\
\text { anteriores, así como para garantizar } \\
\text { obligaciones de pago de otras } \\
\text { entidades y se dicta }\end{array}$ & Economía & $\begin{array}{l}\text { Gubernamental } \\
\text { (Ministerio de } \\
\text { Hacienda) }\end{array}$ & $17 / 09 / 2015$ & $30 / 12 / 2015$ \\
\hline \multicolumn{6}{|c|}{ Proyectos de Ley Estatutaria } \\
\hline 16 & $\begin{array}{l}\text { Por medio de la cual se regula el } \\
\text { derecho fundamental a la salud y } \\
\text { se dictan otras disposiciones. [Ley } \\
\text { estatutaria de reforma a la salud]" }\end{array}$ & $\begin{array}{l}\text { Seguridad Social } \\
\text { y salud }\end{array}$ & $\begin{array}{l}\text { Gubernamental } \\
\text { (Ministerio de } \\
\text { Salud) }\end{array}$ & $19 / 03 / 2013$ & $16 / 02 / 2015$ \\
\hline \multicolumn{6}{|c|}{ Proyectos de Acto Legislativo o de Reforma Constitucional } \\
\hline 17 & $\begin{array}{l}\text { Por medio del cual se adopta una } \\
\text { reforma de equilibrio de poderes } \\
\text { y reajuste institucional y se dictan } \\
\text { otras disposiciones. [Equilibrio de } \\
\text { poderes] }\end{array}$ & Rama Ejecutiva & $\begin{array}{l}\text { Gubernamental } \\
\text { (Ministerio } \\
\text { del Interior y } \\
\text { Ministerio de } \\
\text { Justicia) }\end{array}$ & $03 / 09 / 2014$ & $01 / 07 / 2015$ \\
\hline 18 & $\begin{array}{l}\text { Por el cual se reforma el artículo } \\
221 \text { de la Constitución Política de } \\
\text { Colombia. [Justicia penal militar] }\end{array}$ & $\begin{array}{l}\text { Seguridad, } \\
\text { defensa y fuerza } \\
\text { pública }\end{array}$ & $\begin{array}{l}\text { Gubernamental } \\
\text { (Ministerio de } \\
\text { Defensa) }\end{array}$ & $01 / 10 / 2014$ & $01 / 07 / 2015$ \\
\hline
\end{tabular}

Fuente: Congreso Visible, 2016. www.congresovisible.org.

Sobre las leyes sancionadas, se puede notar que varias de ellas fueron radicadas antes de que el actual Congreso entrara en labores, es decir, antes del 20 de julio de 2014. Esas iniciativas (nueve) se habían presentado en el cuatrienio anterior (2010-2014). De las nueve que se radicaron en el actual período, una fue el Plan Nacional de Desarrollo para el período 2014-2018. Este plan fue llamado “Todos por un nuevo país", y los tres ejes sobre los que gira son la paz, la equidad y la educación. ${ }^{9}$ Otra ley sustantiva que

$9 \quad$ Ley 1753 de 2015, "Por la cual se expide el Plan Nacional de Desarrollo: todos por un nuevo país", en Diario Oficial $N^{o}$ 49538. http:/ / www.achc.org.co/documentos/prensa/LEY-1753-15\%20Plan\%20Nacional\%20de\%20 Desarrollo\%202014\%20-\%202018.pdf. 
fue sancionada en diciembre de 2015 fue la que definió el Presupuesto General de la Nación de 2016. Por otro lado, dos reformas constitucionales se aprobaron en julio de 2015. Una de ellas hace una reforma a la Justicia Penal Militar que busca ampliar el fuero de los militares en un eventual contexto de posconflicto.

La otra reforma constitucional fue un reajuste institucional para buscar un mayor equilibrio entre las ramas del poder público. La discusión en torno a esta iniciativa ocupó gran parte del tiempo de los congresistas desde el momento en que fue radicada, hasta su aprobación tras ocho debates. Uno de los cambios más importantes de esta reforma fue la eliminación de la reelección presidencial que se había aprobado en 2005 durante el primer gobierno del presidente Álvaro Uribe Vélez. El exmandatario fue el primer beneficiado de esa figura, y Juan Manuel Santos el segundo. El próximo Presidente que será elegido en 2018 no podrá aspirar a su reelección.

Finalmente, una ley estatutaria de reforma al sistema de salud también se sancionó en 2015 tras arduos debates en el Congreso. Más adelante en este artículo (sección 6), veremos que algunas de las leyes sancionadas fueron demandadas ante la Corte Constitucional de la rama judicial.

\section{RESULTADOS DE ELECCIONES SUBNACIONALES}

El 25 de octubre de 2015 se realizaron elecciones regionales y locales para el período 2016-2019. Se eligieron 32 gobernadores y 418 diputados en el nivel departamental, y 1.103 alcaldes y 12.063 concejales en el nivel local. ${ }^{10}$ Estas elecciones gozaron de una particular importancia por el contexto político de las negociaciones de paz entre el Gobierno Nacional y las FARC-EP, que según lo declaró Santos en septiembre de 2015, culminarán con la firma del acuerdo final en marzo de 2016.

En estas elecciones compitieron los partidos de la Unidad Nacional (v.g., los de la coalición del gobierno PSUN, PL y CR) con el nuevo partido de oposición, el CD, liderado por el actual senador y expresidente Álvaro Uribe Vélez (2002-2010). Dado que el líder y su partido han sido opositores al proceso de paz, su capital político en el nivel nacional y en el local, podría constituirse en un obstáculo en la etapa de la implementación de los acuerdos. En esta sección describimos brevemente los principales resultados de las elecciones de 2015 y analizamos la composición del sistema de partidos en cada instancia elegida, a partir de dos indicadores, a saber: la participación electoral y el número efectivo de partidos (NEP).

10 En total, según datos oficiales de la Registraduría Nacional del Estado Civil, se presentaron para estas elecciones 112.872 candidatos, discriminados de la siguiente manera: Para gobernaciones un total de 144 inscritos; para alcaldías un total de 4539 inscritos; para la Asamblea un total de 3444 inscritos en 320 listas; y para el Concejo un total de 90274 inscritos en 8844 listas. En este apartado no se analizan las elecciones a JAL (Junta Administradora Local); un cuerpo colegiado submunicipal para el caso de los corregimientos, comunas o localidades en los distintos municipios colombianos según la Ley 136/94. 
Hacer un análisis sobre todo lo ocurrido durante las elecciones regionales excede las pretensiones de este texto. Por esta razón nos concentramos acá en algunos aspectos que consideramos relevantes. En primer lugar, observamos cómo quedó distribuido el poder político en las regiones más afectadas por el conflicto armado y cuál fue el clima electoral en estos territorios.

Observamos que en departamentos afectados históricamente por el conflicto (v.g., Caquetá, Nariño, Cauca, Arauca, Chocó, Norte de Santander), fueron elegidos candidatos que no respaldan el proceso de paz. Estos resultados pueden generarle dificultades políticas al presidente Santos y a su coalición en la etapa de la implementación de los acuerdos de la paz territorial que se está negociando en La Habana. Un escenario emblemático fue el departamento de Caquetá, en donde las dos alcaldías de las ciudades más importantes (v.g., San Vicente del Caguán y Florencia) fueron ganadas por el $\mathrm{CD}$, que orientó su campaña en la seguridad ciudadana y la confianza inversionista (Verdad Abierta, 2015).

En segundo lugar, algunos departamentos fueron afectados por la presencia de grupos al margen de la ley, que constriñeron el comportamiento de los votantes. En Arauca y Chocó, actores armados ilegales interfirieron en el proceso electoral. Según la Misión de Observación Electoral (MOE), al menos 59 municipios de estos departamentos estuvieron bajo riesgo extremo de que ocurriera fraude electoral (MOE, 2015). Por otro lado, en otros 21 departamentos se presentaron cerca de 150 candidatos con cuestionamientos y problemas con la justicia (PARES, 2015). Algunos políticos recibieron apoyos directos de sectores de la ilegalidad, particularmente de bandas criminales derivadas del paramilitarismo o del narcotráfico, y compitieron durante estos comicios o intentaron elegirse en "cuerpo ajeno". Ejemplos de esto son los siguientes: el alcalde de Yopal, capital del Departamento de Casanare, fue elegido desde la cárcel; en Valle del Cauca, Guaviare, Santander y Magdalena, fueron elegidos gobernadores investigados por parapolítica o por enriquecimiento ilícito y narcotráfico (El Tiempo, 2015).

En tercer lugar, el actual vicepresidente, Germán Vargas Lleras, ratificó su poder en estas elecciones. Su partido Cambio Radical (CR) obtuvo gran respaldo en la Costa Caribe. Ganó las gobernaciones de Magdalena, La Guajira, y Sucre, y las alcaldías de las capitales de La Guajira (v.g., Riohacha) y de Atlántico (v.g., Barranquilla). A su vez, eligió mandatarios cercanos a su partido, vía coaliciones en las gobernaciones de Atlántico, Cesar y en la alcaldía de Valledupar. En la capital del país su pulso electoral también fue fundamental para que Enrique Peñalosa fuera elegido alcalde mayor. Lo anterior muestra que el vicepresidente no solo goza de un capital electoral propio, sino también que tiene capacidad política para competir por la presidencia en 2018 (Revista Semana, 2015).

Este panorama muy favorable para el vicepresidente, contrasta con uno poco halagador para el uribismo y para la izquierda democrática. El CD no logró capitalizar sus cerca siete millones de votos obtenidos en las elecciones presidenciales de 2014 en el nivel local. Fracasó en apuestas que hizo para las alcaldías de Bogotá y Medellín, y para la gobernación de Antioquia. Solamente logró ganar una gobernación (la de Casanare) y 76 alcaldías. En algunos casos, formó coaliciones con otros partidos para aumentar 
las posibilidades de triunfo. Estos resultados desfavorables dejan al uribismo en una posición débil con miras a las elecciones presidenciales de 2018, y la vez le resta margen de maniobra como partido opositor del proceso de paz. El escenario para la izquierda es aún más desalentador. El Polo Democrático Alternativo (PDA) y la Unión Patriótica (UP), los dos partidos de izquierda más importantes del país, no tuvieron buen desempeño. La izquierda perdió la alcaldía de Bogotá, que había logrado mantener durante tres administraciones seguidas (Revista Semana, 2015b).

Otro aspecto interesante en estas elecciones tiene que ver con un fenómeno que empezó a darse en 2011 con la formación de coaliciones interpartidarias para las elecciones uninominales (v.g., gobernaciones y alcaldías), y con la aparición de muchos candidatos independientes. La posibilidad de lanzar candidaturas a estos cargos en coaliciones fue una fórmula exitosa en estos comicios. Muchas de estas fueron formadas por partidos que hacen parte de la coalición nacional. Algunos ejemplos fueron las gobernaciones de Meta, Norte de Santander, Boyacá, Huila, Córdoba, Putumayo, entre otras. Por otro lado, en algunas de las ciudades más importantes del país fueron elegidos outsiders que se presentaron a través de movimientos ciudadanos independientes. Tal fue el caso de los candidatos ganadores a las alcaldías en Cali, Bogotá, Bucaramanga, Medellín y Pasto, entre otros (La Silla Vacía, 2015; 2015b). La obtención de poder político a través de coaliciones, o de manera independiente, genera incertidumbre sobre dos aspectos. En primer lugar, no es claro a qué electorado responden gobernantes que son elegidos en coaliciones de partidos que no necesariamente coinciden en sus agendas programáticas. En segundo lugar, aquellos elegidos de manera independiente, y sin contar con el respaldo de los partidos que obtuvieron poder en los cuerpos colegiados, tendrán altos niveles de incertidumbre frente a los niveles de gobernabilidad.

Finalmente, vale la pena observar el desempeño que tuvieron las mujeres en estas elecciones. En total se inscribieron 41.507, de las cuales fueron elegidas 133 como alcaldesas. Este número representó un leve aumento con respecto a 2011 cuando fueron elegidas 108 mujeres en estos cargos. De las 32 gobernaciones, 4 fueron ganadas por mujeres en esta ocasión (El Heraldo, 2015). La Tabla 3.1 resume el desempeño electoral de los partidos políticos que participaron en las elecciones de 2015.

Tabla 3.1. Resultados electorales 2015 por partido político

\begin{tabular}{lcccccccc}
\hline & $\begin{array}{c}\text { Votación } \\
\text { gobernaciones }\end{array}$ & $\begin{array}{c}\text { Gobernaciones } \\
\text { ganadas }\end{array}$ & $\begin{array}{c}\text { Votación } \\
\text { asambleas }\end{array}$ & $\begin{array}{c}\text { Curules } \\
\text { asambleas }\end{array}$ & $\begin{array}{c}\text { Votación } \\
\text { alcaldías }\end{array}$ & $\begin{array}{c}\text { Alcaldías } \\
\text { ganadas }\end{array}$ & $\begin{array}{c}\text { Votación } \\
\text { concejos }\end{array}$ & $\begin{array}{c}\text { Curules } \\
\text { concejos }\end{array}$ \\
\cline { 2 - 8 } & $\begin{array}{c}\text { Total } \\
\text { votos } \\
(\%)\end{array}$ & $\begin{array}{c}\text { Total } \\
\text { gobernaciones } \\
(\%)\end{array}$ & $\begin{array}{c}\text { Total } \\
\text { votos } \\
(\%)\end{array}$ & $\begin{array}{c}\text { Total } \\
\text { asambleas } \\
(\%)\end{array}$ & $\begin{array}{c}\text { Total } \\
\text { votos } \\
(\%)\end{array}$ & $\begin{array}{c}\text { Total } \\
\text { alcaldías } \\
(\%)\end{array}$ & $\begin{array}{c}\text { Total } \\
\text { votos } \\
(\%)\end{array}$ & $\begin{array}{c}\text { Total } \\
\text { concejos } \\
(\%)\end{array}$ \\
\hline Partido & 1.383 .030 & 4 & 2.152 .425 & 84 & $\begin{array}{c}2.012 .713 \\
(11)\end{array}$ & 154 & $\begin{array}{c}2.567 .560 \\
(14)\end{array}$ & $\begin{array}{c}(15,2) \\
(17.082\end{array}$ \\
Liberal & $(10)$ & $(12,5)$ & $(17,7)$ & $(20,1)$ & $(17,3)$ \\
Partido & 396.979 & 1 & 1.801 .979 & 58 & 1.419 .633 & 158 & $\begin{array}{c}2.199 .737 \\
(13)\end{array}$ & 1.966 \\
Conservador & $(2,9)$ & $(3,1)$ & $(14,8)$ & $(13,9)$ & $(7,8)$ & $(14,3)$ & $(13)$ & $(16,3)$ \\
\hline
\end{tabular}




\begin{tabular}{|c|c|c|c|c|c|c|c|c|}
\hline & $\begin{array}{c}\text { Votación } \\
\text { gobernaciones }\end{array}$ & $\begin{array}{l}\text { Gobernaciones } \\
s \text { ganadas }\end{array}$ & $\begin{array}{l}\text { Votación } \\
\text { asambleas }\end{array}$ & $\begin{array}{c}\text { Curules } \\
\text { asambleas }\end{array}$ & $\begin{array}{l}\text { Votación } \\
\text { alcaldías }\end{array}$ & $\begin{array}{l}\text { Alcaldías } \\
\text { ganadas }\end{array}$ & $\begin{array}{l}\text { Votación } \\
\text { concejos }\end{array}$ & $\begin{array}{l}\text { Curules } \\
\text { concejos }\end{array}$ \\
\hline $\begin{array}{l}\text { Partido } \\
\text { Político }\end{array}$ & $\begin{array}{c}\text { Total } \\
\text { votos } \\
(\%)\end{array}$ & $\begin{array}{c}\text { Total } \\
\text { gobernaciones } \\
(\%)\end{array}$ & $\begin{array}{c}\text { Total } \\
\text { votos } \\
(\%)\end{array}$ & $\begin{array}{c}\text { Total } \\
\text { asambleas } \\
(\%)\end{array}$ & $\begin{array}{c}\text { Total } \\
\text { votos } \\
(\%)\end{array}$ & $\begin{array}{c}\text { Total } \\
\text { alcaldías } \\
(\%)\end{array}$ & $\begin{array}{c}\text { Total } \\
\text { votos } \\
(\%)\end{array}$ & $\begin{array}{c}\text { Total } \\
\text { concejos } \\
(\%)\end{array}$ \\
\hline $\begin{array}{l}\text { Unión } \\
\text { Patriótica }\end{array}$ & $\begin{array}{c}27.508 \\
(0,2)\end{array}$ & 0 & $\begin{array}{c}48.284 \\
(0,4)\end{array}$ & $\begin{array}{l}0 \\
0\end{array}$ & $\begin{array}{c}56.536 \\
(0,3)\end{array}$ & $\begin{array}{l}0 \\
0\end{array}$ & $\begin{array}{c}103.143 \\
(0,6)\end{array}$ & $\begin{array}{c}20 \\
(0,2)\end{array}$ \\
\hline $\mathrm{AICO}$ & $\begin{array}{c}50.407 \\
(0,4)\end{array}$ & $\begin{array}{c}1 \\
(3,1)\end{array}$ & $\begin{array}{c}84.521 \\
(0,7)\end{array}$ & $\begin{array}{c}4 \\
(1)\end{array}$ & $\mathrm{N} / \mathrm{A}$ & $\mathrm{N} / \mathrm{A}$ & $\begin{array}{c}546.583 \\
(3,2)\end{array}$ & $\begin{array}{l}368 \\
(3,1)\end{array}$ \\
\hline ASI & $\begin{array}{c}65.916 \\
(0,5)\end{array}$ & 0 & $\begin{array}{c}437.942 \\
(3,6)\end{array}$ & $\begin{array}{c}17 \\
(4,1)\end{array}$ & $\begin{array}{c}457.012 \\
(2,5)\end{array}$ & $\begin{array}{c}37 \\
(3,4)\end{array}$ & $\begin{array}{c}949.305 \\
(5,6)\end{array}$ & $\begin{array}{l}732 \\
(6,1)\end{array}$ \\
\hline MIRA & $\mathrm{N} / \mathrm{A}$ & $\mathrm{N} / \mathrm{A}$ & $\begin{array}{c}289.837 \\
(2,4)\end{array}$ & $\begin{array}{c}8 \\
(1,9)\end{array}$ & $\mathrm{N} / \mathrm{A}$ & $\mathrm{N} / \mathrm{A}$ & $\begin{array}{c}349.485 \\
(2,1)\end{array}$ & $\begin{array}{c}44 \\
(0,4)\end{array}$ \\
\hline $\begin{array}{l}\text { Movimientos } \\
\text { ciudadanos }\end{array}$ & $\begin{array}{c}4.689 .469 \\
(33,8)\end{array}$ & $\begin{array}{c}10 \\
(31,25)\end{array}$ & $\begin{array}{c}14.710 \\
(0,1)\end{array}$ & $\begin{array}{c}2 \\
(0,5)\end{array}$ & $\begin{array}{c}4.670 .402 \\
(25,5)\end{array}$ & $\begin{array}{c}95 \\
(8,6)\end{array}$ & $\begin{array}{c}686.551 \\
(4,1)\end{array}$ & $\begin{array}{c}114 \\
(0,9)\end{array}$ \\
\hline $\begin{array}{l}\text { Cambio } \\
\text { Radical }\end{array}$ & $\begin{array}{c}1.060 .330 \\
(7,7)\end{array}$ & $\begin{array}{c}5 \\
(15,6)\end{array}$ & $\begin{array}{c}1.703 .791 \\
(14)\end{array}$ & $\begin{array}{c}64 \\
(15,3)\end{array}$ & $\begin{array}{c}1.807 .807 \\
(9,9)\end{array}$ & $\begin{array}{c}134 \\
(12,1)\end{array}$ & $\begin{array}{c}2.266 .395 \\
(13,4)\end{array}$ & $\begin{array}{l}1.704 \\
(14,1)\end{array}$ \\
\hline PDA & $\begin{array}{c}108.226 \\
(0,8)\end{array}$ & 0 & $\begin{array}{c}435.121 \\
(3,6)\end{array}$ & $\begin{array}{c}9 \\
(2,2)\end{array}$ & $\begin{array}{c}201.130 \\
(1,1)\end{array}$ & $\begin{array}{c}6 \\
(0,5)\end{array}$ & $\begin{array}{c}690.425 \\
(4,1)\end{array}$ & $\begin{array}{r}236 \\
(2)\end{array}$ \\
\hline $\begin{array}{l}\text { Partido } \\
\text { Verde }\end{array}$ & $\begin{array}{c}211.547 \\
(1,5)\end{array}$ & 0 & $\begin{array}{c}890.442 \\
(7,3)\end{array}$ & $\begin{array}{c}28 \\
(6,7)\end{array}$ & $\begin{array}{c}461.928 \\
(2,5)\end{array}$ & $\begin{array}{c}24 \\
(2,2)\end{array}$ & $\begin{array}{c}1.328 .122 \\
(7,9)\end{array}$ & $\begin{array}{l}878 \\
(7,3)\end{array}$ \\
\hline PSUN & $\begin{array}{c}1.631 .177 \\
(11,8)\end{array}$ & $\begin{array}{c}2 \\
(6,3)\end{array}$ & $\begin{array}{c}2.311 .325 \\
(19)\end{array}$ & $\begin{array}{c}89 \\
(21,3)\end{array}$ & $\begin{array}{c}2.003 .874 \\
(11)\end{array}$ & $\begin{array}{c}182 \\
(16,5)\end{array}$ & $\begin{array}{c}2.418 .645 \\
\quad(14,3)\end{array}$ & $\begin{array}{l}2.154 \\
(17,9)\end{array}$ \\
\hline Progresistas & $\mathrm{N} / \mathrm{A}$ & $\mathrm{N} / \mathrm{A}$ & $\mathrm{N} / \mathrm{A}$ & $\mathrm{N} / \mathrm{A}$ & $\mathrm{N} / \mathrm{A}$ & $\mathrm{N} / \mathrm{A}$ & $\begin{array}{c}58.744 \\
(0,3)\end{array}$ & $\begin{array}{c}1 \\
(0)\end{array}$ \\
\hline $\begin{array}{l}\text { Coaliciones } \\
\text { partidistas }\end{array}$ & $\begin{array}{c}2.806 .116 \\
(20,2)\end{array}$ & $\begin{array}{c}8 \\
(25)\end{array}$ & $\mathrm{N} / \mathrm{A}$ & $\mathrm{N} / \mathrm{A}$ & $\begin{array}{c}3.003 .773 \\
(16,4)\end{array}$ & $\begin{array}{c}207 \\
(18,8)\end{array}$ & $\mathrm{N} / \mathrm{A}$ & $\mathrm{N} / \mathrm{A}$ \\
\hline $\begin{array}{l}\text { Opción } \\
\text { Ciudadana }\end{array}$ & $\begin{array}{c}189.505 \\
(1,4)\end{array}$ & 0 & $\begin{array}{c}644.099 \\
(5,3)\end{array}$ & $\begin{array}{c}18 \\
(4,3)\end{array}$ & $\begin{array}{c}699.356 \\
(3,8)\end{array}$ & $\begin{array}{c}50 \\
(4,5)\end{array}$ & $\begin{array}{c}1.021 .111 \\
(6)\end{array}$ & $\begin{array}{l}867 \\
(7,2)\end{array}$ \\
\hline $\begin{array}{l}\text { Centro } \\
\text { Democrático }\end{array}$ & $\begin{array}{c}1.085 .755 \\
(7,8)\end{array}$ & $\begin{array}{c}1 \\
(3,1)\end{array}$ & $\begin{array}{c}1.211 .966 \\
(10)\end{array}$ & $\begin{array}{c}33 \\
(7,9)\end{array}$ & $\begin{array}{c}1.488 .807 \\
(8,1)\end{array}$ & $\begin{array}{c}56 \\
(5,1)\end{array}$ & $\begin{array}{c}1.150 .343 \\
(6,8)\end{array}$ & $\begin{array}{l}574 \\
(4,8)\end{array}$ \\
\hline MAIS & $\begin{array}{c}151.612 \\
(1,1)\end{array}$ & 0 & $\begin{array}{c}134.893 \\
(1,1)\end{array}$ & $\begin{array}{c}3 \\
(0,7)\end{array}$ & N/A & $\mathrm{N} / \mathrm{A}$ & $\begin{array}{c}542.562 \\
(3,2)\end{array}$ & $\begin{array}{l}323 \\
(2,7)\end{array}$ \\
\hline
\end{tabular}

Fuente: Registraduría Nacional del Estado Civil 2015.

Para concluir esta sección, analizamos los resultados de las elecciones a la luz de los dos indicadores mencionados más arriba. En la Tabla 3.2 mostramos los niveles de participación electoral, ${ }^{11}$ y en la Tabla 3.3 mostramos el NEP para cada elección.

11 La variable participación la operacionalizamos a partir del porcentaje de votos válidos (votos por partidos más votos blanco) emitidos en una circunscripción determinada. 
Tabla 3.2. Niveles de participación electoral

\begin{tabular}{lcccccc}
\hline Corporación & $\begin{array}{c}\text { Potencial } \\
\text { sufragantes }\end{array}$ & Sufragantes & $\begin{array}{c}\text { Votos } \\
\text { válidos }\end{array}$ & $\begin{array}{c}\text { Votos en } \\
\text { blanco }\end{array}$ & Votos nulos & $\begin{array}{c}\text { Tarjetas no } \\
\text { marcadas }\end{array}$ \\
\hline Concejos & 33.792 .602 & 19.853 .730 & 18.162 .670 & 1.124 .411 & 897.613 & 793.447 \\
& & $(58,7 \%)$ & $(53,7 \%)$ & $(3,3 \%)$ & $(2,7 \%)$ & $(2,3 \%)$ \\
Alcaldías & 33.792 .602 & 20.089 .321 & 19.115 .084 & 721.047 & 545.021 & 429.216 \\
& & $(59,4 \%)$ & $(56,6 \%)$ & $(2,1 \%)$ & $(1,6 \%)$ & $(1,3 \%)$ \\
Asambleas & 28.393 .823 & 16.995 .677 & 14.196 .366 & 1.889 .119 & 818.192 & 1.981 .119 \\
Gobernaciones & 28.396 .823 & $(59,9 \%)$ & $(50,0 \%)$ & $(6,7 \%)$ & $(2,9 \%)$ & $(7,0 \%)$ \\
& & $(60,196.021$ & 15.147 .611 & 1.197 .249 & 1.654 .045 & 394.365 \\
& & $(53,3 \%)$ & $(4,2 \%)$ & $(5,8 \%)$ & $(1,4 \%)$ \\
\hline
\end{tabular}

Fuente: Registraduría Nacional del Estado Civil.

Como se ve en la tabla, los niveles promedio de participación electoral rondaron el $60 \%$. Al observar los datos más detenidamente, se ven variaciones departamentales significativas. En los departamentos con las ciudades más pobladas (Valle-Cali; AntioquiaMedellín; y Bogotá-capital del país), los niveles de participación son más bajos (casi 10\% menos que el promedio) que aquellos que se dan en departamentos menos poblados (v.g., Casanare, Córdoba y Sucre). Estos últimos presentaron niveles de participación cercanos al 70\% (ver Anexo 1).

En segundo lugar, la Tabla 3.3 muestra información sobre el número efectivo de partidos (NEP). La Gráfica 3 describe la evolución del indicador desde el 2000 hasta el 2015. Este indicador brinda información sobre el nivel de fragmentación del sistema partidista y sobre el nivel de competencia de los mismos (Laakso y Taagepera, 1979). ${ }^{12}$

Tabla 3.3. Número efectivo de partidos promedio en alcaldías, concejos, gobernaciones y asambleas, 2015

\begin{tabular}{lcccccc}
\hline Departamento & $\begin{array}{c}\text { Promedio } \\
\text { alcaldía } \\
\text { (votos) }\end{array}$ & $\begin{array}{c}\text { Promedio } \\
\text { concejo } \\
\text { (votos) }\end{array}$ & $\begin{array}{c}\text { Promedio } \\
\text { concejo } \\
\text { (curules) }\end{array}$ & $\begin{array}{c}\text { Gobernación } \\
\text { (votos) }\end{array}$ & $\begin{array}{c}\text { Asamblea } \\
\text { (votos) }\end{array}$ & $\begin{array}{c}\text { Asamblea } \\
\text { (curules) }\end{array}$ \\
\hline Amazonas & 3,60 & 8,20 & 6,70 & 3,6 & 9,70 & 9,30 \\
Antioquia & 2,70 & 5,80 & 4,70 & 2,4 & 6,80 & 6,10 \\
Arauca & 2,50 & 6,30 & 4,90 & 2,4 & 6,00 & 4,20 \\
Atlántico & 2,50 & 5,70 & 4,70 & 2,3 & 4,80 & 3,60 \\
Bogotá & 3,90 & 9,20 & 8,20 & $\mathrm{~N} / \mathrm{A}$ & $\mathrm{N} / \mathrm{A}$ & $\mathrm{N} / \mathrm{A}$ \\
Bolívar & 2,40 & 5,60 & 4,90 & 1,9 & 6,60 & 4,30 \\
\hline
\end{tabular}

12 La variable NEP es una fórmula matemática destinada a contar los partidos electoralmente/legislativamente relevantes; fórmula: se calcula a partir de una unidad (1) dividida por la sumatoria de las proporciones de voto/escaños obtenidas por cada partido, elevadas al cuadrado. 


\begin{tabular}{|c|c|c|c|c|c|c|}
\hline Departamento & $\begin{array}{c}\text { Promedio } \\
\text { alcaldía } \\
\text { (votos) }\end{array}$ & $\begin{array}{c}\text { Promedio } \\
\text { concejo } \\
\text { (votos) }\end{array}$ & $\begin{array}{c}\text { Promedio } \\
\text { concejo } \\
\text { (curules) }\end{array}$ & $\begin{array}{l}\text { Gobernación } \\
\text { (votos) }\end{array}$ & $\begin{array}{l}\text { Asamblea } \\
\text { (votos) }\end{array}$ & $\begin{array}{c}\text { Asamblea } \\
\text { (curules) }\end{array}$ \\
\hline Boyacá & 2,50 & 5,20 & 4,40 & 2,7 & 6,30 & 5,10 \\
\hline Caldas & 2,80 & 4,50 & 3,50 & 2,3 & 5,60 & 4,10 \\
\hline Caquetá & 2,80 & 6,80 & 5,50 & 3,4 & 9,10 & 7,10 \\
\hline Casanare & 3,40 & 6,20 & 5,30 & 2,5 & 7,20 & 6,40 \\
\hline Cauca & 2,60 & 5,20 & 4,30 & 2,4 & 7,70 & 6,30 \\
\hline Cesar & 2,80 & 7,30 & 6,00 & 1,9 & 7,50 & 5,80 \\
\hline Chocó & 2,60 & 4,70 & 4,20 & 2,7 & 7,10 & 5,30 \\
\hline Córdoba & 2,40 & 6,30 & 5,10 & 1,9 & 4,60 & 3,90 \\
\hline Cundinamarca & 2,80 & 5,80 & 4,70 & 1,9 & 7,20 & 5,30 \\
\hline Guanía & 2,80 & 6,50 & 5,80 & 3,2 & 9,00 & 7,10 \\
\hline Guaviare & 3,30 & 6,70 & 5,10 & 3,3 & 7,60 & 5,80 \\
\hline Huila & 2,90 & 6,10 & 4,80 & 2,6 & 6,80 & 5,50 \\
\hline La Guajira & 2,40 & 7,60 & 6,80 & 1,6 & 6,40 & 5,30 \\
\hline Magdalena & 2,40 & 6,40 & 5,70 & 1,9 & 6,60 & 5,50 \\
\hline Meta & 3,20 & 7,20 & 5,70 & 3,4 & 6,90 & 5,30 \\
\hline Nariño & 2,40 & 5,50 & 4,90 & 2,1 & 7,00 & 5,20 \\
\hline $\begin{array}{l}\text { Norte de } \\
\text { Santander }\end{array}$ & 2,60 & 5,60 & 4,70 & 2,4 & 6,40 & 5,10 \\
\hline Putumayo & 2,90 & 6,30 & 5,10 & 2,6 & 7,70 & 5,80 \\
\hline Quindío & 2,80 & 7,60 & 5,40 & 2,0 & 5,20 & 4,80 \\
\hline Risaralda & 2,60 & 6,00 & 4,80 & 2,1 & 5,80 & 5,10 \\
\hline San Andrés & 2,00 & 5,00 & 3,80 & 3,6 & 6,90 & 3,90 \\
\hline Santander & 2,50 & 5,40 & 4,40 & 2,8 & 8,00 & 7,10 \\
\hline Sucre & 2,40 & 5,70 & 5,00 & 2,2 & 5,40 & 4,80 \\
\hline Tolima & 2,80 & 5,60 & 4,30 & 2,1 & 7,00 & 5,50 \\
\hline Valle del Cauca & 2,90 & 6,60 & 5,30 & 2,6 & 7,40 & 5,70 \\
\hline Vaupés & 2,50 & 4,70 & 4,30 & 1,9 & 5,90 & 5,80 \\
\hline Vichada & 3,50 & 7,60 & 6,60 & 3,1 & 8,00 & 5,80 \\
\hline
\end{tabular}

Fuente: Registraduría Nacional del Estado Civil 2015.

Según lo que muestran los datos, en los cuerpos colegiados el NEP es más alto que en los cargos uninominales. Mientras que los concejos y asambleas muestran un multipartidismo más o menos extremo, en las alcaldías y gobernaciones la competencia suele ser bipartidista. El Gráfico 1 revela que en los últimos 15 años la fragmentación de los cuerpos colegiados, medida a través del NEP, ha aumentado. En el caso de los cargos uninominales la tendencia ha sido más estable. 
Gráfico 1. Evolución promedio del número efectivo de partidos -votos- en Colombia, 2000-2015

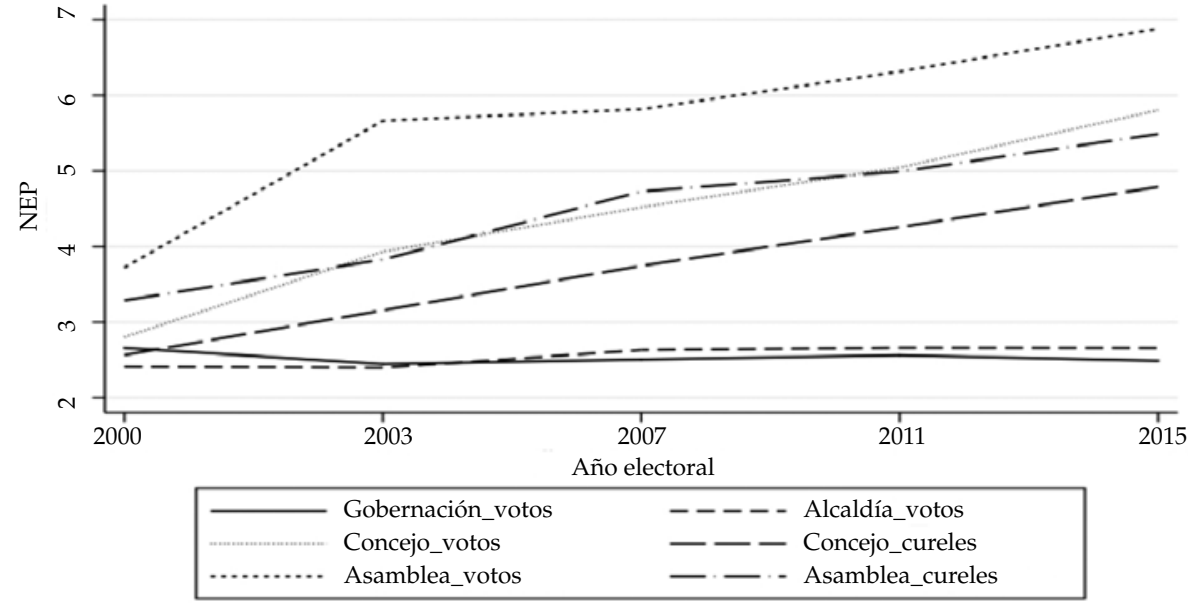

Fuente: Registraduría Nacional del Estado Civil; Pachón y Sánchez, 2014.

\section{PODER EJECUTIVO}

\section{Composición del gabinete}

Al iniciar su segundo período de gobierno, el presidente Juan Manuel Santos renovó gran parte del gabinete. La mayoría de los ministros que ocuparon carteras entre 2010 y 2014 fueron removidos de sus cargos. Solamente las ministras de Relaciones Exteriores (María Ángela Holguín) y de Cultura (Mariana Garcés Córdoba), y los ministros de Hacienda (Mauricio Cárdenas), y de Salud y Protección Social (Alejandro Gaviria), continuaron en sus oficios iniciados en 2010 en los dos primeros casos y en 2012 en los segundos.

Sobre las características del gabinete que estuvo en 2015, se observa lo siguiente. En primer lugar, cinco de dieciséis ministerios, es decir el 31,3\%, fue ocupado por mujeres. Con este porcentaje, el Gobierno Nacional está cumpliendo lo establecido en la ley 581 de 2000 que determina una cuota mínima del 30\% de mujeres en altos cargos que sean de libre nombramiento y remoción. En segundo lugar, la mayor parte de los ministros se identifican con alguno de los partidos de la coalición del gobierno, esto es, la Unidad Nacional (PSUN, PL y CR). Esto se puede inferir por los avales partidistas que ellos han recibido cuando han aspirado a cargos de elección popular, o porque así lo han declarado públicamente. También hay carteras que fueron ocupadas por ministros de otros partidos que no hacen parte de la coalición del gobierno. Tal fue el caso de Hacienda, Minas y Energía, y Trabajo. En los dos primeros están representantes del Partido Conservador, y en el último del Partido Verde (antes de estar en el PV, el ministro había sido del partido de izquierda el Polo Democrático).

La decisión del presidente Santos de incluir partidos que no hacen parte de su coalición en ministerios de tanto peso político, está relacionada con diferentes estrategias. Por 
un lado, con la necesidad de sumar apoyos dentro del Congreso para aumentar las posibilidades de tener un tránsito legislativo exitoso de reformas impopulares como lo son las tributarias y otras relacionadas. En ese sentido, un ministro conservador con la responsabilidad de definir, formular y ejecutar la política económica del país, es un eslabón valioso para acercar el poder ejecutivo al partido que en el Legislativo se definió como fuerza independiente, una vez Santos ganó la reelección presidencial (ver sección 5). Por otro lado, los antecedentes como líder sindical y exalcalde de Bogotá (2004-2008), en ese entonces del partido de izquierda actualmente más visible -el Polo Democrático-, acercan al Gobierno Nacional a uno de los partidos de oposición dentro del Congreso. Estas estratégicas coinciden con lo que la literatura ha planteado sobre el tema: los Presidentes toman decisiones racionales en la conformación de su gabinete para con ello aumentar las posibilidades de aumentar su éxito en la aprobación de su agenda gubernamental (Neto y Borsani, 2004; Neto, 2006).

En tercer lugar, los ministros de Interior, de Educación, y de Tecnologías de la Información y las Comunicaciones, fueron congresistas antes de desempeñar su actual cargo, y los de Agricultura, Minas y Energía, Comercio, Industria y Turismo; y Vivienda, Ciudad y Territorio; ocuparon alguna otra cartera, o fueron viceministros durante el primer gobierno de Santos. El único ministro sin antecedentes en cargos de elección popular, o en cargos ejecutivos dentro de la administración pública, es quien ocupó el de Justicia hasta marzo de 2016. Antes de iniciar su labor actual estuvo dedicado al ejercicio profesional del derecho penal. Lo anterior muestra un estilo muy político del presidente Santos, que no es diferente al que ha tenido en su relación con los congresistas y con gobernantes en el nivel regional. A continuación presentamos una lista de los ministros que estuvieron durante 2015 en el gabinete y agregamos información básica sobre sus trayectorias.

\section{Ministerio del Interior}

Juan Fernando Cristo Bustos (1964, masculino, Partido Liberal). Inició con el segundo período de gobierno de Santos en el 2014. Es abogado. Cuenta con una amplia trayectoria parlamentaria. Fue presidente del Senado hasta su nombramiento como ministro del Interior y ha ocupado varios cargos en el sector público.

\section{Ministerio de Relaciones Exteriores}

María Ángela Holguín Cuellar (s.i., femenino, independiente). Inició con el primer período de gobierno en 2010. Es politóloga. Ha ocupado cargos en el sector público y en el privado.

\section{Ministerio de Hacienda y Crédito Público}

Mauricio Cárdenas Santamaría (1962, masculino, Partido Conservador). Inició a mediados del primer período del gobierno de Santos, luego de haber sido jefe de la cartera de Minas y Energía entre 2011 y 2012. Es economista. Ha ocupado otros cargos en el sector público y privado. 


\section{Ministerio de Defensa Nacional}

Luis Carlos Villegas (1957, masculino, Partido Liberal). Inició con el segundo gobierno en 2015 en reemplazo de Luis Carlos Pinzón, quien ocupó la cartera desde 2010. Es abogado. Ha ocupado cargos en el sector público y privado. Fue jefe negociador en el Proceso de Paz de La Habana en 2013, y luego nombrado embajador de Colombia en Washington hasta mayo de 2015.

\section{Ministerio de Agricultura y Desarrollo Rural}

Aurelio Iragorri Valencia (1966, masculino, Partido Social de Unidad Nacional). Inició con el segundo gobierno del presidente Santos, luego de haber sido viceministro y ministro del Interior en la etapa final del primer mandato del Presidente. Es abogado. Ha ocupado cargos en el sector público y privado.

\section{Ministerio de Salud y de la Protección Social}

Alejandro Gaviria Uribe (s.i, masculino, independiente). Ingeniero civil con estudios en economía. Inició a mediados del primer gobierno, en septiembre de 2012. Ha ocupado cargos en el sector público y privado.

\section{Ministerio de Trabajo}

Luis Eduardo Garzón (1951, masculino, Partido Verde). Inició con el segundo gobierno. Es abogado. Ha ocupado cargos en el sector público y privado. Fue alcalde de Bogotá y ocupó cargos en la primera administración del presidente Santos.

\section{Ministerio de Minas y Energía}

Tomás González Estrada (s.i., masculino, Partido Conservador). Inició con el segundo gobierno. Fue viceministro de Energía e Hidrocarburos durante el primer mandato del presidente Santos. Es economista. Ha ocupado cargos en el sector público y privado.

\section{Ministerio de Comercio, Industria y Turismo}

Cecilia Álvarez Correa Glen (s.i., femenino, Partido Social de Unidad Nacional). Inició en el segundo período de gobierno. Anteriormente fue ministra de Transporte (20122014). Es ingeniera industrial y especialista en finanzas privadas. Ha ocupado cargos en el sector público y privado.

\section{Ministerio de Educación Nacional}

Gina Parody (1973, femenino, Partido Social de Unidad Nacional). Inició con el segundo gobierno, después de haber ocupado cargos públicos durante la primera administración 
del presidente Santos (Alta Consejería para Bogotá y Directora del SENA). Ha ocupado cargos de elección popular (senadora de la República).

\section{Ministerio de Ambiente y Desarrollo Sostenible}

Gabriel Vallejo López (s.i., masculino, Partido Social de Unidad Nacional). Inició con el segundo gobierno. Ha ocupado cargos en el sector público y privado. Antes de ser nombrado ministro fue director del Departamento para la Prosperidad Social.

\section{Ministerio de Vivienda, Ciudad y Territorio}

Luis Felipe Henao Cardona (1979, masculino, Partido Cambio Radical). Inició con el segundo gobierno, después de ocupar el cargo de viceministro para la Participación, en el Ministerio del Interior durante el primer mandato del presidente Santos. También fue viceministro de vivienda entre 2012 al 2014. Es abogado. Ha ocupado cargos en el sector privado.

\section{Ministerio de Tecnologías de la Información y las Comunicaciones}

David Luna Sánchez (1975, masculino, Partido Liberal). Inició en esta cartera con el segundo gobierno de Santos, luego de haber ocupado cargos en el Ministerio de Trabajo y en la Alta Consejería para las Regiones durante el primer gobierno. Es abogado. Ha ocupado cargos de elección popular y ha trabajado en el sector privado.

\section{Ministerio de Transporte}

Natalia Abello Vives (s.i., femenino, Partido Cambio Radical). Inició con el segundo gobierno. Es abogada. Ha ocupado cargos en el sector público.

\section{Ministerio de Cultura}

Mariana Garcés Córdoba (s.i., femenino, independiente). Inició con el primer gobierno. Es abogada. Ha ocupado cargos en el sector público.

\section{Ministerio de Justicia}

Yesid Reyes Alvarado (s.i., masculino, independiente). Inició con el segundo gobierno. Es abogado. Ha desempeñado en el sector privado.

\section{Análisis de funcionamiento}

El gabinete ministerial no se puede analizar como un cuerpo homogéneo. Al contrario, los ministerios se diferencian entre sí en variados aspectos, algunos de los cuáles son los siguientes: el tamaño de la organización; el nivel de incidencia sobre el diseño y ejecución de políticas públicas; la visibilidad que tienen ante la opinión pública a través de los 
medios de comunicación; el presupuesto con el que cuentan para ejecutar acciones; la relación que tienen con el Congreso de la República en la presentación de iniciativas legislativas y en actividades de control político, entre otros. Sin duda, los ministerios con mayor peso político son el de Hacienda; el del Interior; el de Defensa; y el de Justicia. De hecho, las siete leyes que fueron sancionadas durante 2015, que originalmente fueron de iniciativa gubernamental, las radicaron estos cuatro ministerios. Por su parte, los ministerios de Educación y el de Vivienda han liderado proyectos diseñados para favorecer a los sectores de la sociedad menos favorecidos. Los dos más sobresalientes son los programas mencionados más arriba: "Ser Pilo Paga" y las "Cien mil viviendas gratis". El Ministerio de Salud también es otro que resuena, así como el de Tecnologías de la Información y las Comunicaciones. El Ministerio de Relaciones Exteriores suele ser muy visible por el rol preponderante que el Presidente le da a esta cartera con el ánimo de establecer, fortalecer, y mejorar relaciones con los países de los diferentes continentes.

Los Ministerios de Trabajo, el de Transporte, el de Agricultura, y el de Medio Ambiente a pesar de ser estratégicos por los temas que trabajan, no lideraron proyectos significativos durante 2015, o no lograron resolver eficientemente problemáticas relevantes.

\section{PODER LEGISLATIVO}

El Congreso de la República actual se eligió en marzo de 2014 para un período de cuatro años (2014-2018). La Tabla 5.1 muestra la composición partidaria en cada una de las Cámaras, y el poder político relativo que tiene cada partido. También subraya los partidos que hacen parte de la coalición del gobierno de Juan Manuel Santos, quien fue reelecto en la segunda vuelta electoral de junio del mismo año con el 53\% de los votos.

Tabla 5.1. Composición del poder político en el Congreso de la República, 2014-2018

\begin{tabular}{|c|c|c|c|c|}
\hline \multirow[t]{2}{*}{ Partido Político } & \multicolumn{2}{|c|}{ Senado } & \multicolumn{2}{|c|}{$\begin{array}{c}\text { Cámara de } \\
\text { Representantes }\end{array}$} \\
\hline & Curules & $\%$ & Curules & $\%$ \\
\hline Liberal Colombiano* & 17 & 16,7 & 39 & 23,5 \\
\hline Movimiento Político Cien por Ciento por Colombia & 0 & 0,0 & 3 & 1,8 \\
\hline Conservador Colombiano & 18 & 17,6 & 27 & 16,3 \\
\hline MIRA & 0 & 0,0 & 3 & 1,8 \\
\hline Opción Ciudadana & 5 & 4,9 & 6 & 3,6 \\
\hline Partido Social de Unidad Nacional - Partido de la U* & 21 & 20,6 & 37 & 22,3 \\
\hline Centro Democrático & 20 & 19,6 & 19 & 11,4 \\
\hline Movimiento Alternativo Indígena y Social - MAIS & 1 & 1,0 & 0 & 0,0 \\
\hline Cambio Radical* & 9 & 8,8 & 16 & 9,6 \\
\hline Alianza Verde & 5 & 4,9 & 6 & 3,6 \\
\hline Alianza Social Independiente & 1 & 1,0 & 1 & 0,6 \\
\hline
\end{tabular}




\begin{tabular}{|c|c|c|c|c|}
\hline \multirow{2}{*}{ Partido Político } & \multicolumn{2}{|c|}{ Senado } & \multicolumn{2}{|c|}{$\begin{array}{c}\text { Cámara de } \\
\text { Representantes }\end{array}$} \\
\hline & Curules & $\%$ & Curules & $\%$ \\
\hline Fundación Ébano de Colombia Funeco & 0 & 0,0 & 2 & 1,2 \\
\hline Polo Democrático Alternativo & 5 & 4,9 & 3 & 1,8 \\
\hline Movimiento de Integración Regional - MIR & $\mathrm{N} / \mathrm{A}$ & $\mathrm{N} / \mathrm{A}$ & 1 & 0,6 \\
\hline Por un Huila Mejor & $\mathrm{N} / \mathrm{A}$ & $\mathrm{N} / \mathrm{A}$ & 1 & 0,6 \\
\hline Autoridades Indígenas de Colombia AICO & $\mathrm{N} / \mathrm{A}$ & $\mathrm{N} / \mathrm{A}$ & 2 & 1,2 \\
\hline Total & 102 & 100,0 & 166 & 100,0 \\
\hline
\end{tabular}

*Partidos de la Unidad Nacional, o coalición del gobierno.

Fuente: Registraduría Nacional del Estado Civil, 2014.

En comparación con el Congreso que estuvo en el poder durante el primer mandato de Santos (2010-2014), el actual se diferencia en dos aspectos en términos de configuración del poder. El primero de ellos, es que el tamaño de la coalición es menor ahora. La Unidad Nacional del período anterior reunía el 76\% del poder político, y estaba conformada por el Partido Social de Unidad Nacional (PSUN), el Partido Liberal (PL), Cambio Radical (CR), y el Partido Conservador (PC). La actual coalición ha gozado de la presencia de los tres primeros, pero no del último partido. El PC se declaró como una fuerza independiente al iniciar el nuevo período del actual Congreso. A pesar de esta situación, en el primer año y medio de labores, otros partidos que no iniciaron el período formalmente integrados a la coalición de gobierno (el Verde y Mira, particularmente), favorecieron a las mayorías, y apoyaron varias de las iniciativas de origen legislativo y ejecutivo.

La segunda diferencia se relaciona con el tamaño y las características de la oposición. En el período anterior, el partido contradictor del gobierno fue el Polo Democrático Alternativo (PDA), de tendencia ideológica de izquierda. Este ocupó el 7,8\% y 3,1\% del poder en el Senado y Cámara de Representantes, respectivamente. Actualmente conserva un disminuido 4,9\% en Senado y 1,8\% en la Cámara de Representantes. En los dos períodos, el rol más destacado de este partido ha estado enfocado en la función de control político al poder ejecutivo.

La otra característica distintiva en la composición del actual Congreso ha sido la entrada de un segundo y nuevo partido de oposición, liderado por el expresidente y actual senador, Álvaro Uribe Vélez. El Centro Democrático (CD) obtuvo la segunda más alta votación en el Senado (la cuarta en la Cámara), y logró ocupar 20 escaños (y 19 en la Cámara de Representantes). Ubicado a la derecha del espectro ideológico, se ha caracterizado por su posición crítica frente a varias de las iniciativas promovidas por los partidos de la coalición y por los ministros del gabinete del gobierno. El partido ha presentado varios proyectos de ley y de reforma constitucional, pero no ha sido exitoso en el trámite de estos. A pesar de que ha demostrado ser el más disciplinado en el Congreso, con una actuación permanente en bancada, su poder relativo no ha sido suficiente para sacar adelante las iniciativas que ha radicado. Con algunas pocas excepciones, ha actuado 
independiente de cualquier otra colectividad (Congreso Visible, 2015). Si bien esto ha contribuido a debates ideológicos dentro de la institución, no ha favorecido al partido en la posibilidad de avanzar hasta el final en el trámite de sus iniciativas. En algunos casos, y a pesar de estar en una orilla ideológica opuesta al PDA, se ha unido con este para cuestionar al gobierno en decisiones que se han tomado en torno a temas relacionados con el proceso de paz, y asuntos relacionados con las fuerzas militares.

En síntesis, el actual Congreso de la República tiene una composición política en la que se distinguen partidos ideológicos que la opinión pública define como de izquierda (v.g., el PDA), de derecha (v.g. el CD), y de centro-derecha (v.g., PSUN, PL, CR, PV, MIRA, OC). Esta característica es distintiva en el actual período. En comparación con otros momentos, hoy es más claro qué partidos se identifican con qué postura ideológica.

\section{Análisis de su funcionamiento}

Cada una de las Cámaras del Congreso de la República está compuesta por siete comisiones constitucionales permanentes. Estas son integradas por los senadores y los representantes a la Cámara, quienes tienen la obligación de pertenecer a una única comisión de estas y de permanecer en ella todo el cuatrienio. La elección de los miembros de las comisiones, que se hace a través del sistema de cociente electoral, tiene en cuenta la proporcionalidad de escaños obtenidos por cada partido. Cada comisión tiene una mesa directiva que es integrada por un presidente y por un vicepresidente que se eligen para períodos de un año, sin la posibilidad de ser reelectos. La Tabla 5.2 presenta información de los temas sobre los que trabaja cada comisión, y la cantidad de integrantes que las componen en cada una de las Cámaras.

Tabla 5.2. Comisiones constitucionales del Congreso de la República

\begin{tabular}{lllc}
\hline Comisión & \multicolumn{1}{c}{ Temas } & $\begin{array}{c}\text { \# de integrantes \# de integrantes } \\
\text { en Senado } \\
\text { en Cámara }\end{array}$ \\
\hline Primera & $\begin{array}{l}\text { Reforma constitucional; organización territorial; } \\
\text { reglamentos de los organismos de control; normas } \\
\text { generales sobre contratación administrativa, de } \\
\text { los derechos, garantías y deberes; rama legislativa; } \\
\text { políticas para la paz; y asuntos étnicos. }\end{array}$ & & \\
Segunda & $\begin{array}{l}\text { Política internacional; defensa nacional y fuerza } \\
\text { pública; comercio exterior e integración económica; } \\
\text { fronteras; extranjeros; y monumentos públicos. }\end{array}$ & 19 & \\
Tercera & $\begin{array}{l}\text { Hacienda y crédito público; impuestos y } \\
\text { contribuciones; exenciones tributarias; régimen } \\
\text { monetario; sistema de Banca Central; regulación } \\
\text { económica; mercado de valores; régimen de } \\
\text { cambios; actividades financieras, bursátiles, } \\
\text { aseguradoras, y cambiarias; los asuntos relativos } \\
\text { a Planeación Nacional. }\end{array}$ & 13 & \\
\hline
\end{tabular}




\begin{tabular}{|c|c|c|c|}
\hline Comisión & Temas & $\begin{array}{c}\text { \# de integrantes } \\
\text { en Senado }\end{array}$ & $\begin{array}{c}\text { \# de integrantes } \\
\text { en Cámara }\end{array}$ \\
\hline Cuarta & $\begin{array}{l}\text { Leyes orgánicas de presupuesto; control fiscal; } \\
\text { patentes y marcas; organización de establecimientos } \\
\text { públicos nacionales; control de calidad y precios; } \\
\text { y contratación administrativa. }\end{array}$ & 15 & 27 \\
\hline Quinta & $\begin{array}{l}\text { Régimen agropecuario; ecología y medio ambiente; } \\
\text { recursos naturales; adjudicación y recuperación } \\
\text { de tierras; recursos ictiológicos y asuntos del } \\
\text { mar; minas y energía; y corporaciones autónomas } \\
\text { regionales. }\end{array}$ & 13 & 19 \\
\hline Sexta & $\begin{array}{l}\text { Comunicaciones; tarifas; calamidades públicas; } \\
\text { servicios públicos; medios de comunicación; } \\
\text { investigación científica y tecnología; órbita } \\
\text { geoestacionaria; sistemas digitales de comunicación } \\
\text { e informática; espacio aéreo; obras públicas; } \\
\text { transporte; turismo; educación y cultura. }\end{array}$ & 13 & 18 \\
\hline Séptima & $\begin{array}{l}\text { Estatuto del servidor público; régimen salarial y } \\
\text { prestacional del servicio público; organizaciones } \\
\text { sindicales; seguridad social; cajas de previsión; } \\
\text { fondos prestacionales; carrera administrativa; } \\
\text { recreación; deportes; salud; vivienda; economía } \\
\text { solidaria; asuntos de la mujer y de la familia. }\end{array}$ & 14 & 19 \\
\hline
\end{tabular}

Fuente: Congreso Visible. http://www.congresovisible.org/comisiones/\#tab=1.

Las comisiones que más peso político tienen son la primera, la tercera, la cuarta y la séptima. En la primera se inician las discusiones sobre reformas constitucionales, las terceras y cuartas tienen a su cargo los temas económicos y de presupuesto nacional; y la séptima discute temas de salud. Usualmente quienes integran estas comisiones son congresistas con mucho poder político y electoral, y con experiencia previa en el Congreso. Aunque la permanencia por todo el cuatrienio en la misma comisión está establecida en el reglamento de la institución, ha habido casos en los que los congresistas negocian informalmente entre ellos el intercambio entre una y otra. Por ejemplo, ha habido momentos en los que quienes aspiran a ocupar la presidencia del Senado o de la Cámara -que suelen ser políticos con peso electoral y político ocupantes de puestos en las comisiones más poderosas-, intercambian su puesto con algún otro congresista de alguna comisión menos relevante a cambio de su apoyo (Gil, 2013).

El trámite legislativo de todo proyecto de ley o de reforma constitucional se inicia en las comisiones constitucionales. Allí se da el primer debate. Una vez aprobado, el segundo debate pasa a la plenaria de la Cámara en la que inició originalmente la iniciativa. Posteriormente, el tercer debate se da en la comisión de la otra Cámara y el cuarto en la plenaria de esta. Mientras que los proyectos de ley ordinarios requieren estos cuatro debates para convertirse en ley, los de reforma constitucional requieren cuatro debates adicionales. Adicionalmente, mientras que los primeros requieren mayoría 
simple para su aprobación, esto es, que la mayoría de los asistentes en el recinto voten favorablemente, las segundas (así como el reglamento del Congreso, las normas sobre el presupuesto y el Plan Nacional de Desarrollo) requieren mayoría absoluta: la decisión es adoptada por la mayoría de los votos de los integrantes del cuerpo colegiado (comisión o plenaria), y no solamente por los asistentes a la sesión en las que se da la votación. La mayoría calificada, esto es, dos tercios de los votos de los integrantes, se requiere para la aprobación o reforma de leyes que concedan amnistías o indultos.

Durante el segundo semestre del 2015, es decir en la primera parte de la segunda legislatura del Congreso, ${ }^{13}$ fueron radicados un total de 286 proyectos de ley, de los cuales 256 fueron de iniciativa de los congresistas; 27 del gobierno y 3 de otros autores.

Además de las comisiones constitucionales y de las plenarias de Senado y Cámara de Representantes, el Congreso cuenta con comisiones legales que son creadas por ley, y se encargan de asuntos específicos distintos a los de competencia de las comisiones constitucionales permanentes.

\section{RELACIÓN ENTRE LOS PODERES DEL ESTADO (FORMAL Y DE HECHO)}

En 2015 se aprobó una reforma constitucional de equilibrio de poderes. El propósito de esta es lograr un balance más acentuado entre las ramas, pues tras la adopción de la reelección presidencial en 2005 este se vio afectado. Después de haber sido sancionada como ley de la República, la reforma ha sido demandada en diferentes ocasiones por parte de funcionarios de cargos públicos, entre ellos, el Fiscal General de la Nación. En diciembre de 2015 la Corte Constitucional no había fallado en contra de la misma.

Durante 2015 se demandaron algunas de las leyes sancionadas en este cuatrienio. Algunas de ellas fueron la reforma al estatuto tributario; el Presupuesto de Rentas; la Ley de Regalías; la Ley de Infraestructura; y el Plan Nacional de Desarrollo, todas de iniciativa gubernamental. En todos los casos la Corte Constitucional tumbó algunos artículos importantes. Por su parte, los congresistas fueron muy activos dentro de estas demandas. Por ejemplo, el actual presidente del Senado, Luis Fernando Velasco, fue uno de los actores que demandó la reforma al estatuto tributario. Congresistas del opositor PDA intervinieron en demandas contra leyes de autoría de otros partidos, y de su propia autoría. Por otro lado, durante el mismo año, el Congreso respondió eficientemente a los llamados que la Corte le hizo para que legislara sobre algunos temas. Uno de ellos que tuvo resonancia en los medios fue el de la regulación y formalización de algunos aspectos laborales para las trabajadoras domésticas. Al observar estos casos, se puede decir que la relación entre el Congreso y la Corte ha sido muy dinámica durante este período. Más allá de la idea común de que la Corte Constitucional es antagonista del

13 Los períodos ordinarios del Congreso empiezan en las siguientes fechas. La primera parte de la legislatura inicia el 20 de julio y termina el 16 de diciembre. La segunda parte empieza el 16 de marzo y termina el 20 de junio. 
Congreso, se puede afirmar que la misma se ha constituido como otro escenario político importante (Agudelo, Gómez y Niño, 2015; Celemín, 2015).14

En cuanto a la relación entre el Congreso y el Gobierno Nacional, quedó claro en la sección 5 de este artículo, que el segundo cuenta con una coalición de tamaño significativo en el Congreso, y que gracias a esta, los ministros que han presentado iniciativas legislativas han sido relativamente exitosos. Aunque el poder ejecutivo es mucho menos activo que el legislativo en la radicación de proyectos, es más eficiente en lograr que los que presenta sean exitosos y pasen sin problema todo el trámite legislativo. Frente al control político que ejerce el Congreso sobre la rama ejecutiva, es claro que es la oposición la más preocupada por llamar a los ministros del gabinete a que rindan cuentas. De las citaciones programadas durante el segundo semestre de 2015, se llevaron a cabo el 63\%. Este porcentaje es cercano al comportamiento promedio a lo largo del tiempo. Los ministros más citados el primer semestre de la segunda legislatura (de julio 20 a diciembre 16, 2015) fueron el de Hacienda; el de Salud; el de Medio Ambiente; el de Salud; y el de Minas y Energías. Los temas de preocupación se relacionaron con el presupuesto nacional; las minas y su impacto en el medio ambiente; la seguridad en la frontera con Venezuela; la tregua unilateral y el cese bilateral del fuego en el contexto del proceso de paz; y la crisis hospitalaria en el sector de la salud (Cerinza y Niño, 2015). Un tema de control político que promovió durante 2015 el PL, fue la moción de censura al ministro de Hacienda por su intención de vender a privados una de las compañías estatales con más activos en el país (v.g., Isagén). Sin embargo, al igual que en el pasado, la propuesta no prosperó por las dificultades procedimentales que tiene su trámite, y por la configuración de poder político favorable al Ejecutivo (Santamaría y Wills-Otero, 2013).

\section{RELACIÓN ENTRE LOS DISTINTOS NIVELES DE GOBIERNO}

Durante 2015 quedó claro, que los políticos que ocupan cargos en el nivel nacional tienen relaciones estrechas con los que están en el nivel subnacional (departamentos y municipios). Las elecciones de octubre fueron una oportunidad para observar cómo los congresistas hicieron trabajo político en sus regiones para apoyar a candidatos de sus partidos (o de sus afectos) en la campaña electoral que se llevó a cabo entre agosto y octubre. Tanto representantes a la Cámara de las diferentes circunscripciones departamentales, como los senadores con electorados cautivos regionalmente, manifestaron públicamente apoyo por los candidatos de su preferencia. Por su parte, el Presidente de la República también fue activo durante el proceso electoral al hacer énfasis en la importancia de apoyar desde lo regional y lo local el proceso de paz que se lleva a cabo entre el Gobierno Nacional y las FARC-EP. La idea detrás de sus llamados fue la necesidad de contar con respaldo político por parte de los mandatarios locales en la etapa de la implementación de los acuerdos. 


\section{EVALUACIÓN GENERAL SOBRE EL FUNCIONAMIENTO Y CALIDAD DE LA DEMOCRACIA}

Para concluir, cerramos este artículo haciendo un balance positivo, pero matizado, sobre el funcionamiento y la calidad de la democracia en Colombia. La revisión de los hechos y dinámicas políticas que acá resaltamos, muestran un país que goza de instituciones formales que definen procesos políticos, y que responden a interacciones (que se esperan) entre los diferentes actores que componen el sistema. El desarrollo del proceso electoral de 2015; el trámite legislativo que surten los proyectos que se radican en el Congreso de la República; el control político que este último ejerce sobre el Ejecutivo; y el rol activo que cumple la Corte Constitucional en su deber de controlar las otras ramas del poder, entre otros, son ejemplos de los efectos que tiene el diseño institucional vigente sobre los actores que hacen parte las diferentes instituciones.

Ahora bien, el país enfrenta retos inmensos frente a la posibilidad de que el Gobierno Nacional firme un acuerdo final de paz con las FARC-EP para dar paso a un escenario de posconflicto. En dicha transición, se probará la fortaleza institucional y la voluntad política de los actores (tanto políticos como ciudadanos) para encaminar el país hacia un escenario en el que habrá que hacer ajustes que permitan la reintegración exitosa de los excombatientes, así como su participación en la vida política del país. Sin voluntad política ni disposición para conciliar posiciones polarizadas, el proceso de reconciliación se vería en riesgo, y el país entero sufriría las consecuencias de volver a un escenario de guerra e intolerancia.

\section{REFERENCIAS}

Agudelo, Diana; Gómez, Luisa María y Niño, María Isabel. 2015. “¿Un tenso equilibrio”. Congreso Visible. En: http://www.congresovisible.org/agora/post/un-tenso-equilibrio/7929/.

Borda, Sandra. 2015. "2015: una política exterior para la paz". Razón Pública. En: http:/ /www.razonpublica. com/index.php/conflicto-drogas-y-paz-temas-30/9114-2015-una-pol\%C3\%ADtica-exterior-para-la-paz.

Celemín Caicedo y Andrea, Yenny. 2015. "Democracia, control horizontal y procedimiento legislativo: un análisis desde el sistema jurídico colombiana". Tesis para optar el título de Doctora en Derecho. Universidad de los Andes.

Cerinza, Andrea y María Isabel Niño. 2015. "La lupa del Congreso en elecciones". Congreso Visible. En: http://congresovisible.org/agora/post/la-lupa-del-congreso-en-elecciones/7931/.

Cox, Gary y Morgenstern, Scott. 2001. "Latin America's Reactive Assemblies and Proactive Presidents". Comparative Politics 33 (2): 171-189.

Congreso Visible. 2015. "El primer año del Congreso en cifras". En: http://congresovisible.org/agora/ post/el-primer-ano-del-congreso-en-cifras-i/7392 (18 de junio).

2015. “Lo que dejó el primer año de labores del Congreso". En: http:/ / congresovisible.org/agora/ post/lo-que-dejo-el-primer-ano-de-labores-del-congreso/7421/.

2015. "Una oposición pragmática". En: http://congresovisible.org/agora/post/ una-oposicion-pragmatica/7941/.

El Heraldo. 2015. "Santos, aciertos y desaciertos en 2015". En: http://www.elheraldo.co/politica/ santos-aciertos-y-desaciertos-en-2015-235248.

2015. "133 mujeres fueron electas alcaldesas en las regionales de 2015". En: http:/ /www.elheraldo. co/politica/133-mujeres-fueron-electas-alcaldesas-en-las-regionales-de-2015-228122. 
El Tiempo. 2015. "Preso e investigados, candidatos triunfadores de las elecciones". En: http://www.eltiempo. $\mathrm{com} /$ politica/justicia/elecciones-2015-triunfan-candidatos-investigados-o-en-la-carcel/16413091.

. 2015b. "Gobernadores se unen para frenar el chikunguña en el país". En: http:/ /www.eltiempo. com/colombia/otras-ciudades/cumbre-de-gobernadores-contra-el-chikunguna/15130555.

Fundación Paz \& Reconciliación (PARES). 2015. "Informe: Lo que hemos ganado". [En linea]. http:// www.pares.com.co/carrusel/lo-que-hemos-ganado/.

Gil, Beatriz Elena. 2013. "La conformación de las Comisiones Constitucionales en el Congreso de la República. ¿Qué cambios se han dado en el cuatrienio 2010-2014, y qué factores los explican?". Congreso Visible. [En línea] http://congresovisible.org/agora/post/ la-conformacion-de-las-comisiones-constitucionales-en-el-congreso-de-la-republica-que-cambiosse-han-dado-en-el-cuatrienio-2010-2014-y-que-factores-los-explican/5888/.

La Silla Vacía. 2015. “Los 15 cañonazos electorales del 2015”. En: http://lasillavacia.com/historia/ los-15-canonazos-electorales-del-2015-52109.

2015b. "Los diez fenómenos de estas elecciones". En: http://lasillavacia.com/historia/ los-diez-fenomenos-52212.

Laakso, Markku y Taagepera, Rein,. (1979). "Effective Number of Parties: A Measure with Application to West Europe". Comparative Political Studies 12: 3-27.

Misión de Observación Electoral (MOE). 2015. "Riesgos por fraude y por factores de violencia confluyen en 204 municipios del país". En: http:/ /moe.org.co/prensa/comunicados-de-prensa/515-riesgospor-fraude-y-por-factores-de-violencia-confluyen-en-204-municipios-del-pais-moe.

Neto, Octavio Amorin y Borsani, Hugo. 2004. "Presidents and cabinets: The political determinants of fiscal behavior in Latin America". Studies in Comparative International Development 39 (1): 3-27.

Neto, Octavio Amorim. 2006. "The Presidential Calculus Executive Policy Making and Cabinet Formation in the Americas". Comparative Political Studies 39 (4): 415-440.

Revista Portafolio. 2015. "El trabajo de aplicar la tributaria este año". En: http://www.portafolio.co/ economia/reforma-tributaria-2015.

Revista Semana. 2015. "Germán es el man: la victoria del vicepresidente en las urnas". En: http:/ / www.semana. com/nacion/articulo/german-vargas-lleras-el-ganador-de-las-elecciones-regionales-2015/448217-3.

2015b. "¿Qué pasó camaradas?: la derrota de la izquierda". En: http:/ / www.semana.com/nacion/ articulo/resultados-elecciones-2015-la-derrota-de-la-izquierda/448218-3.

.2015c. "Cronología del proceso de paz entre el Gobierno y las FARC". En: http:/ /www.semana. $\mathrm{com} /$ nacion/articulo/linea-de-tiempo-del-proceso-de-paz-de-las-farc-gobierno/443570-3.

. 2015d. "Empresarios preocupados por situación económica". En: http://www.semana.com/ economia/articulo/empresarios-preocupados-por-situacion-economica-en-colombia/452949-3.

Santamaría, Nicolás y Wills-Otero, Laura. 2013. "La moción de censura en Colombia: evento poco probable" Razón Pública. En: http:/ / www.razonpublica.com/index.php/politica-y-gobierno-temas-27/7151la-moci\%C3\%B3n-de-censura-en-colombia-evento-poco-probable.html.

Verdad Abierta. 2015. “QQué va a pasar con los municipios del posconflicto?”. [En linea]. http://www. verdadabierta.com/desde-regiones/6043-que-va-a-pasar-con-los-municipios-del-posconflicto.

Laura Wills-Otero es PhD, profesora asociada y directora de Congreso Visible del Departamento de Ciencia Política de la Universidad de los Andes de Bogotá, Colombia. E-mail: 1.wills21@uniandes.edu.co.

Carlos Andrés Hoyos es investigador del Centro de Memoria Histórica y M.A en Ciencia Política de la Universidad de los Andes de Bogotá, Colombia. E-mail: ca.hoyos970@gmail.com. 


\section{ANEXO 1 \\ PARTICIPACIÓN ELECTORAL PROMEDIO POR DEPARTAMENTO PARA CADA TIPO DE ELECCIÓN}

\begin{tabular}{|c|c|c|c|c|}
\hline Departamento & $\begin{array}{c}\text { Participación } \\
\text { alcaldía }\end{array}$ & $\begin{array}{c}\text { Participación } \\
\text { gobernación }\end{array}$ & $\begin{array}{l}\text { Participación } \\
\text { concejo }\end{array}$ & $\begin{array}{c}\text { Participación } \\
\text { asamblea }\end{array}$ \\
\hline Amazonas & $\begin{array}{c}23.212 \\
(60,7 \%)\end{array}$ & $\begin{array}{l}26.349 \\
(59,6 \%)\end{array}$ & $\begin{array}{l}23.109 \\
(60,5 \%)\end{array}$ & $\begin{array}{l}26.180 \\
(59,2 \%)\end{array}$ \\
\hline Antioquia & $\begin{array}{c}2.426 .805 \\
(54,3 \%)\end{array}$ & $\begin{array}{c}2.382 .576 \\
(53,3 \%)\end{array}$ & $\begin{array}{c}2.360 .903 \\
(52,8 \%)\end{array}$ & $\begin{array}{c}2.321 .484 \\
(51,9 \%)\end{array}$ \\
\hline Arauca & $\begin{array}{l}102.530 \\
(59,3 \%)\end{array}$ & $\begin{array}{l}102.202 \\
(59,1 \%)\end{array}$ & $\begin{array}{l}102.161 \\
(59,1 \%)\end{array}$ & $\begin{array}{l}102.612 \\
(59,3 \%)\end{array}$ \\
\hline Atlántico & $\begin{array}{c}1.064 .683 \\
(50,5 \%)\end{array}$ & $\begin{array}{c}1.063 .912 \\
(60,5 \%)\end{array}$ & $\begin{array}{c}1.024 .521 \\
(58,2 \%)\end{array}$ & $\begin{array}{c}1.031 .393 \\
(58,6 \%)\end{array}$ \\
\hline Bogotá & $\begin{array}{c}2.811 .209 \\
(51,6 \%)\end{array}$ & $\mathrm{N} / \mathrm{A}$ & $\begin{array}{c}2.687 .899 \\
(49,3 \%)\end{array}$ & $\mathrm{N} / \mathrm{A}$ \\
\hline Bolívar & $\begin{array}{l}895.112 \\
(60,4 \%)\end{array}$ & $\begin{array}{l}890.044 \\
(60,1 \%)\end{array}$ & $\begin{array}{l}840.897 \\
(56,7 \%)\end{array}$ & $\begin{array}{l}844.882 \\
(57,1 \%)\end{array}$ \\
\hline Boyacá & $\begin{array}{l}646.333 \\
(69,9 \%)\end{array}$ & $\begin{array}{l}644.438 \\
(69,7 \%)\end{array}$ & $\begin{array}{l}637.545 \\
(68,9 \%)\end{array}$ & $\begin{array}{l}634.155 \\
(68,6 \%)\end{array}$ \\
\hline Caldas & $\begin{array}{l}455.080 \\
(58,6 \%)\end{array}$ & $\begin{array}{l}453.332 \\
(58,3 \%)\end{array}$ & $\begin{array}{l}453.657 \\
(58,4 \%)\end{array}$ & $\begin{array}{l}450.108 \\
(57,9 \%)\end{array}$ \\
\hline Caquetá & $\begin{array}{c}155.892 \\
(56,06 \%)\end{array}$ & $\begin{array}{l}157.246 \\
(56,6 \%)\end{array}$ & $\begin{array}{l}157.962 \\
(56,8 \%)\end{array}$ & $\begin{array}{l}158.006 \\
(56,8 \%)\end{array}$ \\
\hline Casanare & $\begin{array}{l}193.320 \\
(74,9 \%)\end{array}$ & $\begin{array}{l}193.752 \\
(75,1 \%)\end{array}$ & $\begin{array}{l}194.914 \\
(75,6 \%)\end{array}$ & $\begin{array}{l}194.131 \\
(75,3 \%)\end{array}$ \\
\hline Cauca & $\begin{array}{l}574.060 \\
(62,8 \%)\end{array}$ & $\begin{array}{l}566.699 \\
(61,9 \%)\end{array}$ & $\begin{array}{l}549.259 \\
(60,1 \%)\end{array}$ & $\begin{array}{l}544.651 \\
(59,5 \%)\end{array}$ \\
\hline Cesar & $\begin{array}{l}474.891 \\
(64,9 \%)\end{array}$ & $\begin{array}{l}474.335 \\
(64,9 \%)\end{array}$ & $\begin{array}{l}488.307 \\
(66,8 \%)\end{array}$ & $\begin{array}{l}481.177 \\
(65,8 \%)\end{array}$ \\
\hline Chocó & $\begin{array}{l}180.693 \\
(61,6 \%)\end{array}$ & $\begin{array}{l}175.749 \\
(59,9 \%)\end{array}$ & $\begin{array}{l}170.766 \\
(58,2 \%)\end{array}$ & $\begin{array}{l}175.097 \\
(59,7 \%)\end{array}$ \\
\hline Córdoba & $\begin{array}{l}841.152 \\
(71,1 \%)\end{array}$ & $\begin{array}{l}838.245 \\
(70,8 \%)\end{array}$ & $\begin{array}{l}774.931 \\
(65,4 \%)\end{array}$ & $\begin{array}{l}778.108 \\
(65,7 \%)\end{array}$ \\
\hline Cundinamarca & $\begin{array}{c}1.138 .464 \\
(65,1 \%)\end{array}$ & $\begin{array}{c}1.132 .314 \\
(64,7 \%)\end{array}$ & $\begin{array}{c}1.106 .287 \\
(63,2 \%)\end{array}$ & $\begin{array}{c}1.101 .857 \\
(62,9 \%)\end{array}$ \\
\hline Guainía & $\begin{array}{c}12.100 \\
(66,4 \%)\end{array}$ & $\begin{array}{l}15.039 \\
(62,7 \%)\end{array}$ & $\begin{array}{c}11.701 \\
(64,3 \%)\end{array}$ & $\begin{array}{c}14.797 \\
(61,7 \%)\end{array}$ \\
\hline Guaviare & $\begin{array}{c}35.203 \\
(62,2 \%)\end{array}$ & $\begin{array}{l}35.006 \\
(61,9 \%)\end{array}$ & $\begin{array}{l}34.863 \\
(61,6 \%)\end{array}$ & $\begin{array}{c}37.794 \\
(61,5 \%)\end{array}$ \\
\hline Huila & $\begin{array}{l}510.839 \\
(65,1 \%)\end{array}$ & $\begin{array}{l}509.647 \\
(64,9 \%)\end{array}$ & $\begin{array}{l}498.301 \\
(63,5 \%)\end{array}$ & $\begin{array}{l}495.581 \\
(63,2 \%)\end{array}$ \\
\hline
\end{tabular}




\begin{tabular}{|c|c|c|c|c|}
\hline Departamento & $\begin{array}{c}\text { Participación } \\
\text { alcaldía }\end{array}$ & $\begin{array}{l}\text { Participación } \\
\text { gobernación }\end{array}$ & $\begin{array}{c}\text { Participación } \\
\text { concejo }\end{array}$ & $\begin{array}{c}\text { Participación } \\
\text { asamblea }\end{array}$ \\
\hline La Guajira & $\begin{array}{l}317.729 \\
(57,6 \%)\end{array}$ & $\begin{array}{l}316.007 \\
(57,3 \%)\end{array}$ & $\begin{array}{l}316.948 \\
(57,5 \%)\end{array}$ & $\begin{array}{l}311.271 \\
(56,5 \%)\end{array}$ \\
\hline Magdalena & $\begin{array}{l}564.753 \\
(63,1 \%)\end{array}$ & $\begin{array}{l}562.513 \\
(62,8 \%)\end{array}$ & $\begin{array}{l}528.459 \\
(58,9 \%)\end{array}$ & $\begin{array}{l}528.162 \\
(58,9 \%)\end{array}$ \\
\hline Meta & $\begin{array}{l}445.540 \\
(67,5 \%)\end{array}$ & $\begin{array}{l}442.485 \\
(67,1 \%)\end{array}$ & $\begin{array}{l}425.843 \\
(64,5 \%)\end{array}$ & $\begin{array}{l}422.143 \\
(63,9 \%)\end{array}$ \\
\hline Nariño & $\begin{array}{l}729.191 \\
(67,9 \%)\end{array}$ & $\begin{array}{l}708.191 \\
(65,9 \%)\end{array}$ & $\begin{array}{l}705.259 \\
(65,7 \%)\end{array}$ & $\begin{array}{l}691.659 \\
(64,4 \%)\end{array}$ \\
\hline Norte de Santander & $\begin{array}{l}644.989 \\
(58,3 \%)\end{array}$ & $\begin{array}{l}642.811 \\
(58,1 \%)\end{array}$ & $\begin{array}{l}650.619 \\
(58,8 \%)\end{array}$ & $\begin{array}{l}644.858 \\
(58,3 \%)\end{array}$ \\
\hline Putumayo & $\begin{array}{l}127.042 \\
(60,9 \%)\end{array}$ & $\begin{array}{l}126.343 \\
(60,6 \%)\end{array}$ & $\begin{array}{l}125.416 \\
(60,2 \%)\end{array}$ & $\begin{array}{l}125.140 \\
(60,1 \%)\end{array}$ \\
\hline Quindío & $\begin{array}{l}275.834 \\
(61,1 \%)\end{array}$ & $\begin{array}{l}275.212 \\
(60,9 \%)\end{array}$ & $\begin{array}{l}276.204 \\
(61,2 \%)\end{array}$ & $\begin{array}{l}274.524 \\
(60,8 \%)\end{array}$ \\
\hline Risaralda & $\begin{array}{l}437.935 \\
(58,3 \%)\end{array}$ & $\begin{array}{l}436.154 \\
(58,1 \%)\end{array}$ & $\begin{array}{l}438.745 \\
(58,4 \%)\end{array}$ & $\begin{array}{l}440.725 \\
(58,7 \%)\end{array}$ \\
\hline San Andrés & $\begin{array}{c}2.912 \\
(67,8 \%)\end{array}$ & $\begin{array}{c}24.880 \\
(52,2 \%)\end{array}$ & $\begin{array}{c}2.993 \\
(69,7 \%)\end{array}$ & $\begin{array}{c}24.730 \\
(51,9 \%)\end{array}$ \\
\hline Santander & $\begin{array}{c}1.061 .269 \\
(65,5 \%)\end{array}$ & $\begin{array}{c}1.059 .517 \\
(65,3 \%)\end{array}$ & $\begin{array}{c}1.043 .732 \\
(64,4 \%)\end{array}$ & $\begin{array}{c}1.037 .697 \\
(63,9 \%)\end{array}$ \\
\hline Sucre & $\begin{array}{l}481.285 \\
(73,8 \%)\end{array}$ & $\begin{array}{c}478.37 \\
(73,4 \%)\end{array}$ & $\begin{array}{l}485.124 \\
(74,4 \%)\end{array}$ & $\begin{array}{l}478.799 \\
(73,4 \%)\end{array}$ \\
\hline Tolima & $\begin{array}{l}630.368 \\
(60,7 \%)\end{array}$ & $\begin{array}{l}627.976 \\
(60,5 \%)\end{array}$ & $\begin{array}{l}631.164 \\
(60,8 \%)\end{array}$ & $\begin{array}{l}621.081 \\
(59,8 \%)\end{array}$ \\
\hline Valle & $\begin{array}{c}1.747 .919 \\
(51,9 \%)\end{array}$ & $\begin{array}{c}1.727 .699 \\
(51,3 \%)\end{array}$ & $\begin{array}{c}1.681 .059 \\
(49,9 \%)\end{array}$ & $\begin{array}{c}1.703 .617 \\
(50,6 \%)\end{array}$ \\
\hline Vaupés & $\begin{array}{c}11.211 \\
(61,5 \%)\end{array}$ & $\begin{array}{c}12.350 \\
(60,4 \%)\end{array}$ & $\begin{array}{c}10.658 \\
(58,5 \%)\end{array}$ & $\begin{array}{c}11.943 \\
(58,4 \%)\end{array}$ \\
\hline Vichada & $\begin{array}{c}26.505 \\
(57,3 \%)\end{array}$ & $\begin{array}{c}26.672 \\
(57,6 \%)\end{array}$ & $\begin{array}{c}26.430 \\
(57,1 \%)\end{array}$ & $\begin{array}{c}27.288 \\
(58,9 \%)\end{array}$ \\
\hline
\end{tabular}


